\title{
Hyperopic Experimentation: Organizations Learning About Managers Learning About Strategies
}

\author{
Scott C. Ganz
}

October 21, 2018

\begin{abstract}
Offline experiments are central to the design-thinking approach to organizational innovation and are also a core practice in evidence-based management. Organizations use experiments to test new strategies in a low stakes setting. Yet organizations also use experiments to evaluate managers who will implement these strategies online. I develop a formal model to demonstrate that these two types of evaluation are fundamentally incompatible. Managers who fear replacement in response to a poor offline outcome will pervert their experiments to maximize the likelihood that they succeed. This saps offline experiments of much of their informational value. I show that if an organization can observe a manager's experimental strategies and the experiment's outcomes and can commit ahead of time to an evaluation and replacement rubric, then it can resolve this principal-agent problem. However, if a manager's experimental strategy cannot be credibly communicated, and thus are evaluated solely based on experimental outcomes, the organization faces two risks in its effort to promote effective offline experiments. If the organization replaces managers based on their offline outcomes, then it risks replacing good managers. If the organization never replaces managers, then it risks retaining bad ones. I demonstrate that when experimental outcomes are more certain, replacing managers based on observed offline outcomes produces the best results. When outcomes are less certain, commitment to retention regardless of offline outcomes is best.
\end{abstract}




\section{Introduction}

Successful organizations continually produce fundamental innovations that fuel growth in the long term Anderson and Tushman, 1990; O'Reilly and Tushman, 2013, Tushman and Anderson, 1986; Tushman and O'Reilly, 1996; Utterback, 1994). Yet, despite the potential payoff from wideranging exploration, organizations struggle to induce members to take big risks with uncertain payoffs. Myopic search, inertial organizational routines, difficulties with cross-unit collaboration, political conflict, and managerial risk aversion all conspire to make organizational innovation overly incremental (Cyert and March, 1963, DiMaggio and Powell, 1983, Gibbons and Roberts, 2012, Hannan and Freeman, 1984, Levitt and March, 1988; Manso, 2011; March, 1991; March and Shapira, 1987: Shapira, 1995). Managers seek smaller, exploitative improvements to existing products, services, and technologies rather than the large, bold innovations that sustain competitive advantage.

One way that organizations try to overcome myopia, risk aversion, and inertial incrementalism is by encouraging managers to experiment "offline." As opposed to "online" search, in which organizations implement costly strategic changes and then observe whether or not they work, offline experiments let organizations observe small-scale tests of alternative strategies before fully committing to a new initiative. Clinical trials by drug companies, pilot testing by management consulting firms, A/B testing by internet search engines, randomized control trials in international development, and weapons prototyping in the defense industry are all examples of offline experiments. Offline experiments reduce the risks associated with adopting a new strategy, because the knowledge gleaned offline can inform the strategies that organizations take online (Csaszar and Levinthal, 2016; Dichtler et al., 1993; Gavetti and Levinthal, 2000; Kelley and Littman, 2001; Lippman and McCall, 1976; Pfeffer and Sutton, 2006b; Winter et al., 2007).

However, offline experimentation brings about a classic agency problem in organizations. Offline experiments not only let managers test alternative strategies, but also let organizations evaluate the competence of the managers. It can be hard for a firm to distinguish a good manager who had bad luck from an incompetent manager (Stinchcombe, 1990). For example, a research scientist whose lab finds null results can get negative performance reviews, because it is hard to know if the results are "real" or reflect bad research design. Prior research on the effect of career concerns on online search demonstrates that managers have an incentive to be incremental, to set more limited but more achievable goals (Aghion and Jackson, 2014; Manso, 2011). 
It is less recognized that the same agency problem can also induce overly exploratory offline search. Failing to achieve an unattainable goal says less about the striver's competence than failing to achieve an attainable one. Indeed, they might get credit for their audacity. Rather than coloring outside the lines, such managers will color "on an entirely different page" (Kelley and Littman, 2001). IDEO general manager Tom Kelley, for example, once described the "joyful failure" of the Enorme phone, an experimental product co-designed with an iconic Italian designer that sought to bring Italian design aesthetics together with Silicon Valley telephone engineering. The effort was undoubtedly innovative: an example of the phone remains in the permanent collection of the Museum of Modern Art in New York. It was also an abject failure as a consumer product. At $\$ 150$ apiece at a time when customers could easily get a phone for a few dollars, there was no consumer demand for the "playful cubist" telephone (Kelley and Littman, 2001). This kind of experimentation is no better for organizations than unamibitious, myopic experimentation is. Further, because prior research concerns overcoming incrementalism and exploitation in the context of online search, the risk of over-exploration in offline search is a novel problem for organizational researchers (Lee and Meyer-Doyle, 2017; Manso, 2011). The challenge in offline experimentation is not merely to get managers to take bigger risks, but also to make them avoid goals that are so ambitious as to be unusable or impractical.

This paper explores this organizational dilemma with a formal model. In the model, the organization delegates an offline experiment to a manager before taking a new initiative online. Offline experiments reveal information about the relationship between strategies and outcomes for the manager and, as such, about the desirability of retaining the manager when implementing the initiative online. Following the experiment, the organization chooses between allowing the manager who experimented to lead the online implementation and removing the manager in favor of an inexperienced replacement. I assume that managers are primarily concerned about their own careers and secondarily about organizational performance. The model demonstrates how career concerns inflamed by the fear of failed experiments combine with information asymmetries to produce ineffective offline experiments. In particular, I show that if managers fear being replaced as a result of a bad offline outcome, they over-experiment in order to decrease the chance of being replaced.

A key implication of the model is that first-best resolution of the agency problem is only possible when both managers' strategies and the outcomes of their experiments are observable 
and the organization can pre-commit to specific replacement regimes. A manager's strategy is rarely observable in practice, though (Stinchcombe, 1990). Absent a commitment to a replacement regime, career concern lead organizations to have a difficult time motivating effective offline search whether experimental strategies are observable or tacit.

A further implication of the model is that the organization can reach second-best solutions when strategies are tacit and the organization can commit to a replacement regime, but the best type of replacement regime depends on the level of uncertainty. In this scenario, the organization faces a classic management trade-off. If the organization commits to retain the manager regardless of the offline outcome, it aligns the manager's preferences with the organization's at the risk of retaining an undesirable manager. If it pre-commits to a set of offline outcomes for which it will replace the manager, it induces an effective offline experiment at the risk of replacing a desirable manager. I demonstrate that as uncertainty grows, it becomes more desirable for organizations to let managers experiment without fear of replacement. In this way, the formal model's predictions jibe with the strategic human resources policies in a number of famously exploratory firms that inhabit highly uncertain innovation environments, including Bell Labs, IDEO, Google, and W.L. Gore (Gertner, 2012; Hamel and Spence, 2010; Kelley and Littman, 2001; Lashinsky, 2006).

\section{Background and Related Work}

Delegated Experimentation, Imperfect Information, and Career Concerns

Organizations face a tension between the need to undertake risky search and the difficulties they face promoting risk taking by their members. Strong inertial forces within organizations and external pressures to conform to existing norms generate status quo bias (DiMaggio and Powell, 1983; Hannan and Freeman, 1984). Myopic managers and organizational incentives in turn promote managerial risk aversion (Gibbons and Roberts, 2012, Holmstrom and Ricart i Costa, 1986; Manso, 2011; March and Shapira, 1987; Shapira, 1995). These varied mechanisms help to explain why organizations tend to be better at exploitative, incremental search than exploratory, uncertain search.

One tactic for increasing risk tolerance in search is an organizational commitment to offline experimentation. Offline experiments allow organization members to look before they leap and to develop a more detailed understanding of the innovation landscape. Offline experiments promote 
"hyperopic" search. Pilot testing and prototyping in particular have been at the core of the designthinking approach to innovation and change. By trying new ideas, seeing what works, and rapidly iterating, organizations can reduce the complexity of a problem and uncover novel solutions (Kelley and Littman, 2001). For example, a Bay Area organization charged with supporting families with children with developmental disabilities used prototyping to improve its service delivery by streamlining how new clients were evaluated. The organization experimented with a Winnebago that took evaluators to applicants' neighborhoods instead of requiring "a daunting series of meetings and examinations in unfamiliar new places" (Sutton and Hoyt, 2016). A process that usually took two to three months was reduced by ten weeks, on average. Although outfitting the organization with a fleet of RVs was a non-starter, the results of the experiment convinced the organization to create a dedicated assessment team in order to reduce the complexity of the initial assessment process and to make social workers more mobile (Sutton and Hoyt, 2016).

Offline experimentation is also central to the literature on evidence-based management. By selecting alternatives, executing small-scale market tests, and carefully measuring outcomes, organizations can overcome decision making biases and political opposition to change (Beshears and Gino, 2014; Pfeffer and Sutton, 2006a b). Pfeffer and Sutton (2006b) describe how Harrah's Las Vegas Hotel \& Casino overturned industry-wide conventional wisdom about the best way to get customers to gamble more through the use of low-stakes experiments. In one experiment, Harrah's offered one group of customers a standard promotional package that included $\$ 30$ in chips and $\$ 95$ in meal and room vouchers and another group an experimental package that only included $\$ 60$ in chips. Contrary to the widely held belief that gamblers are enticed to the tables by fancy meals and entertainment, the second package induced more gambling revenue at a lower cost.

The economics literature on career concerns, however, paints a less rosy picture of organizations' capacity to motivate their employees to explore (Holmstrom, 1999). Managers who are unsure about their competence in a task would prefer not to reveal themselves incompetent. This fear leads managers to forego risk taking, generating inertia, herding behavior, and pandering Aghion and Jackson, 2014, Canes-Wrone et al., 2001; Gibbons and Roberts, 2012).

Career concerns can also make managers over-experiment in offline search. Rather than experimenting with a strategy that they think could work well, a manager may instead experiment with a strategy that they think will go too far. The logic is that observers will attribute fail- 
ure in such circumstances to the difficulty of the task, not the incompetence of the manager. In Lindbergh and Miller (2016), two statistically-inclined baseball bloggers who helped to manage a professional independent league baseball team recount the challenges of getting their players to buy into the non-traditional ways of arranging players on a baseball field that are supported by baseball's outsiders. Lindbergh and Miller experimented with these unusual fielding configurations during a practice game, acknowledging that "if it works, we're confident they'll embrace [our vision]. If it doesn't, we're not confident they'll have the courage to keep trying. And if it's somewhere in between, it probably counts as a loss for us." Lindbergh and Miller required that the team's fielders position themselves unconventionally for every single at-bat during the game. "The point isn't necessarily for it to work," they admitted. "The point is to see where it fails." Because they required the players to be overly experimental, the team evaluated Lindbergh and Miller based on whether they learned something from the experience, rather than on their in-game performance. Offline over-experimentation helped Lindbergh and Miller solidify their influence over the team and its coaches.

An additional complication for organizations is that while offline outcomes may be easily observable, the strategies managers select that produce those outcomes may not be. Strategies may be tacit, that is, understood by the experimenting manager but difficult to communicate Collins, 2010; Kogut and Zander, 1992; Polanyi, 2009). Managers may also lie about strategies in order to make their experiments appear more successful (Stinchcombe, 1990). Absent a mechanism through which organizations can force managers to commit to a strategy before doing the experiment (as is increasingly en vogue in some scientific fields (Nosek and Lakens, 2014)), organizations have to infer an experiment's strategy from its outcome when evaluating the experimenting manager. Tom Wolfe highlights this problem for the Air Force and Navy in his description of test pilots who crash their planes while disregarding military rules about mock dogfighting in the 1940s and 50s: "[I]t was not uncommon for some eager [fighter] jock to try too tight an outside turn and have his engine flame out, whereupon, unable to restart it, he has to eject [...] and he starts thinking about how he can get together with the other guy back at the base in time for the two of them to get their stories straight before the investigation: 'I don't know what happened, sir. I was pulling up after a target run, and it just flamed out on me."' What should the military infer? Is the pilot telling the truth, in which case they should be concerned about faulty engines? Or, is the pilot trying 
to demonstrate that he has the "right stuff," in which case the pilot gratuitously destroyed a very expensive aircraft?

I use a formal model to explore how these three factors - career concerns, imperfect information, and task uncertainty - interact to impact offline experimentation in organizations. The model has two goals. The first is to examine an question previously unexplored in the management literature: why is offline experimentation often ineffectively blue-sky? Second, the model recommends solutions that organizations can use to address the inefficiencies caused by the agency problem, and demonstrates how the right solutions vary with the uncertainty of the task and whether the offline strategy is observable.

\section{Models of Learning and Conflict in Organizations}

I embed these issues of delegation, incomplete information, and career concerns into a model of search over a rugged landscape. In doing so, I bridge the gap between the organization-theoretic and economic approaches to modeling learning in organizations. A tradeoff exists in present scholarship on organizational learning between the researcher's desire to capture the complexity inherent to the process of discovery and the researcher's need to make clear predictions about how changes inside of organizations and in the external environment impact performance. Organizational theory and economics emphasize different sides of this tension. Organizational theory focuses on the relationship between the complexity of search and organizational performance (Davis et al., 2007. Levinthal, 1997, Rivkin, 2000). Organizational and political economics focus on problems associated with collecting and transmitting information within organizations populated by individuals with differing preferences and goals (Callander, 2011a b; Gibbons et al., 2012).

Within organizational theory, there is an emphasis on understanding how organizations react to randomness in the fitness landscape. These stochastic models explore how the uncertainty associated with implementation of novel configurations of organizational inputs combines with various search strategies to impact long-term performance and survival. The basic models in this tradition envision the organization as undertaking random, local search and, through trial-and-error, eventually finding collections of inputs that dominate other local combinations (Levinthal, 1997). Some more recent work has integrated cognitive representations of the fitness landscape that serve as maps for local search. Organizations cannot know precisely how a change to a strategic in- 
put will impact performance, but they may have general or abstract knowledge of the innovation process that makes it seem more likely that a particular change will be performance-enhancing (Csaszar and Levinthal, 2016, Fleming and Sorenson, 2004; Gavetti and Levinthal, 2000; Gavetti et al. 2005). For example, Fleming (2002) describes how the design of Hewlett-Packard's first ink jet printer was inspired by recent work in high temperature physics on "micro jets," but also required a lengthy trial-and-error experimental approach to find a resistor that could both generate extreme heat and withstand long term wear-and-tear. Other recent work has integrated more detailed organizational decision-making processes into this framework. These models highlight how incentive conflict, hierarchical decision-making, and problems with information-sharing impact the capacity of organizations to learn about uncertain alternatives Csaszar and Eggers, 2013, Csaszar and Levinthal, 2016; Rivkin and Siggelkow, 2003; Schilling and Fang, 2014). Both of these newer approaches add realism to organizational learning, but bringing these intra-organizational dynamics into the evolutionary framework requires layering exogenous assumptions about the behavior of individuals inside organizations on top of pre-existing assumptions about organizational search behavior, environmental selection, and the structure of the fitness landscape. Critics of this approach highlight the incompatibility between the strategic motivation of individuals within organizations and non-strategic search by organizations (Callander and Matouschek, 2014; Roberts et al., 2012).

In contrast, organizational and political economics prioritizes detailed examinations of decisionmaking processes inside organizations at the cost of realistic depictions of randomness in the task environment. Economic models emphasize the roles that preference conflict, worker incentives, asymmetric information, and supervisory relationships play in generating suboptimal organizational outcomes. Agency problems in particular are prominent in economic models of decision making and learning under uncertainty (Gibbons et al., 2012). Unlike organizational theory, which relies heavily on evolutionary logic and simulation modeling, economic models of organizational learning are solved in an analytic manner using non-cooperative game theory. Search behavior is driven endogenously by the behavioral assumptions of individual actors in the model. Rational choice search models are limited by the fact that they rely on sparse representations of the complexity of learning, typically using a discrete set of strategic alternatives or a single random parameter that, if revealed, provides a global map of outcomes associated with potential changes to inputs Bendor and Meirowitz, 2004, Callander, 2008; Crawford and Sobel, 1982, Gilligan and Krehbiel, 1987, 1989, 
Manso, 2011). Economic models in which organizations learn about managerial competence use a similarly simplified structure, in which managers are endowed as either competent or incompetent and the organization seeks to reveal a manager's type Aghion and Jackson, 2014; Canes-Wrone et al. 2001).

More recent work in political economics tries to integrate richer representations of the fitness landscape while maintaining the mathematical tractability required to derive closed-form solutions. One innovation is representing the relationship between organizational inputs and outcomes as a unidimensional stochastic process (Callander, 2008, 2011ab). The stochastic process generates rugged uncertainty in the fitness landscape. However, the character of the uncertainty is driven by parameters known to the analyst, which enables formal analysis of search strategy.

The model I develop here leverages this methodological innovation from political economics to combine the strengths of the organization-theoretic and economic modeling approaches. Because the mapping between strategies and outcomes is operationalized by a one-dimensional path of Brownian motion, the managers in my model face stochastic uncertainty, like in organization theory models. Yet because the Brownian path is a specific realization from a well-defined probability distribution, managerial expectations about the performance of untried strategies are analytically tractable. As a result, the manager's search behavior emerges endogenously from their preferences, like in economic models.

Further, the rugged task environment used here improves on prior models in organizational economics by permitting exploration of the link between managerial incentives surrounding tenure, search behavior, and organizational performance. Rather than a manager simply choosing between a risky and a safe option, my model involves selecting from a continuum of interdependent experimental strategies. Rather than an organization facing a choice between a competent and incompetent manager, all managers in my model are capable of producing high quality outcomes. However, some managers have accurate mental models of the task environment that facilitate more effective search. As a result, I make predictions both about how career concerns affect the type of experiments that managers do and about how different experimentation strategies interact with the uncertainty of the task environment to affect organizational performance.

\section{Model}




\section{Illustrative Example: Daniel Libeskind's Master Plan for the World Trade Center}

I begin with an illustrative example to highlight key features and strategic decisions in the model. After the terrorist attack on the World Trade Center (WTC) on September 11, 2001, policymakers charged with the rebuilding effort had to satisfy competing interests with different visions for the site. At the conflict's core was the relative importance of commercial vs. civic goals (Nobel, 2005). Early suggestions for the sixteen acre site included iconic skyscrapers, a memorial, ten million square feet of office space, a transportation hub, a cultural center, a retail mall, a public park, new streets, a hotel, and a residential tower. New York Times reporter Ed Wyatt described the complex uncertainty involved in the planning process: "The decisions about a memorial, the street grid, and whatever commercial development occurs on the site are so intertwined as to be essentially one decision, whose many parts will have to be made almost simultaneously." (Wyatt, 2002 ).

Initial plans from architecture firm Beyer Blinder Belle were criticized as myopically focused on the commercial requirements and lacking a longer-term vision for the iconic public space Goldberger, 2005). According to Washington Post architecture critic Benjamin Forgey: "It is rather like taking the downtown skyline of some average American burg and plopping it in one of the most

prominent and symbolically important sites of our times" (Forgey, 2002). In an effort to induce more creative visions for the master plan, the Lower Manhattan Development Corporation (LMDC) organized an "Innovative Design Study" competition among prominent architecture firms.

The benefits of hyperopic experimentation were well-understood by the LMDC when it set the terms of the design study competition. In the document announcing the search for architects to be invited to submit designs, the LMDC stated the competition was "intended to generate creative and varied concepts to help plan the future of the site" (Goldberger, 2005). Rather than a detailed set of technical requirements, the rules of the competition only included a set of general guidelines and suggestions.

The payoff for the competing architecture firms was the opportunity for the winner to implement their vision for the site. The meager stipend offered to the competition's participants did not nearly cover the costs of developing the proposals. For these top firms, the overlapping government bureaucracies and contentious local politics associated with the rebuilding efforts made the competition frustrating and risky (Goldberger, 2005). Yet, the LMDC made no guarantees that any 
of the firms would be retained once the competition ended. Developer Larry Silverstein, who held the lease for the site, made clear from the beginning that he, not the LMDC, had the final say over the final design for the WTC site.

The chosen winner, designed by Daniel Libeskind, included a 1,776-foot spire housing a "vertical garden" and an open plaza illuminated by a "Wedge of Light" upon which "each year on Sept. 11 between the hours of 8:46 a.m., when the first airplane hit, and 10:28 a.m., when the second tower collapsed, the sun will shine without shadow" (Wyatt, 2003). Libeskind's proposal was undoubtedly hyperopic. It focused almost exclusively on how the space could serve as a memorial. Plans for commercial development were relegated to rough sketches on the boundary.

Silverstein allowed Libeskind to stay on as master planner for the site once Libeskind agreed to collaborate with Silverstein's preferred architect for the design of the buildings. Neither the spire nor the sun-lit memorial came to pass. Libeskind's slender design for the main skyscraper grew in bulk in response to pressure from the developer to add office space and concerns from the government about safety from future terror attacks. But Libeskind's vision nevertheless provided the seeds of a master plan that tied together the varied components of the rebuilt site. Figure 1a, Figure 1b, and Figure 1c compare the original design for Beyer Blinder Belle's "Memorial Garden," Libeskind's proposal, and the final plan, a clear compromise between the two earlier visions Nobel, 2005).

\section{[FIGURE 1 GOES ABOUT HERE]}

My theoretical model captures some of the strategic decisions involved in the LMDC design study competition and Libeskind's proposal. The model begins with a known status quo, akin to the early plans for the WTC site by Beyer Blinder Belle. An organization directs a manager to experiment with an alternative strategy offline. In this case, the organization is the LMDC, the manager is Libeskind, and the offline experiment is his proposal for the master plan. Next, the organization observes the experiment's outcome and decides whether to retain the manager or to engage a different manager to take the project online. Following the presentation of Libeskind's design proposal, the LMDC had the option to retain Libeskind or to replace him with another architecture firm for the final design of the WTC site. Finally, the chosen manager selects an online strategy and implements it. The LMDC retained Libeskind, who altered his original submission to reflect the contractual and safety requirements for the space. 
The basic structure of the model is illustrated in Figure 2. The model has two phases: In the offline phase, the manager experiments with a strategy and an offline outcome is revealed. In the online phase, the organization decides whether to retain the manager who experimented offline or replace the manager with an inexperienced replacement. Then, the selected manager chooses an online strategy, which produces an online outcome that generates a payoff for the organization.

\section{[FIGURE 2 GOES ABOUT HERE]}

\section{Building Rugged Fitness Landscapes}

The model combines core ideas about search on uncertain landscapes that are the basis for many models in organizational theory. The first idea is that hard problems in organizations often involve the search for a middle ground between competing goals. For example, banks seek to balance risk and reward; firms set their optimal production level in response to a downward-sloping demand curve; governments need to collect revenue to fund public projects but also prefer to keep taxes low Arthur, 2016; Ganz, 2018; Pondy, 1992). The optimal balance is hard to find because of uncertainty in the relationship between strategies and outcomes. Banks do not know the true risk profile of their investments; firms do not know the exact demand curve for their consumers; governments can only roughly approximate the marginal benefit of public projects. These search problems are akin to Goldilocks sampling porridge: some strategies are too hot, some are too cold, and some are just right.

A second feature of search is that organizations learn from experience. More similar strategies produce more similar and more certain outcomes than dissimilar ones do. A small change to the top federal income tax rate, for example, will cause a small and predictable change in tax revenue; a large change to the rate will cause a large and unpredictable change in revenue. Also, untried strategies that lie between previously tried strategies have lower uncertainty than those that are outside of the support of prior experience. If a government has prior experience with income tax rates of 30 percent and 40 percent, policymakers will be better able to predict the revenue produced from a tax rate of 35 percent than from 25 or 45 percent.

Finally, the relationship between strategies and outcomes is defined by an unobserved function. Absent other sources of environmental drift and implementation uncertainty, an organization that reproduces the same strategy should also achieve the same outcome. However, this functional relationship between strategies and outcomes is hidden from the organizations searching the landscape. 
Fitness landscapes with these properties are hybrids of the two extreme types contrasted in Levinthal and Warglien (1999). One type of landscape is smooth and single-peaked, illustrated in Figure 3a, The other is maximally rugged and multi-peaked, illustrated in Figure 3b. In the hybrid landscapes in my model, the underlying problem the organization faces is globally singlepeaked in expectation. However, uncertainty driven by unobserved interdependencies endemic to organizational change create local hills and valleys in the landscape's realization. In this way, the landscapes used here are similar to those developed in Winter et al. (2007), illustrated in Figure 3c.

\section{[FIGURE 3 GOES ABOUT HERE]}

I create fitness landscapes using a novel modeling technique developed in Callander (2011a b). Perhaps the simplest way to generate a smooth and single-peaked landscape is through a quadraticloss organizational utility function, $u(y)=-y^{2}$, where $y$ defines an outcome and $u(y)$ defines the organization's payoff associated with that outcome. Utility is maximized at $y=0$ and the undesirability of outcomes distant from 0 grows at an increasing rate.

Uncertainty is incorporated into the model via stochasticity in the functional relationship between strategies, $x$, and outcomes, $y=f(x)$. In classic examples of search in economics, $f(x)$ is a linear function, $1-x+\epsilon$, where $\epsilon$ is an unobserved constant (Bendor and Meirowitz, 2004, Crawford and Sobel, 1982, Gilligan and Krehbiel, 1987). This is the simplest form of uncertainty, because knowledge of any strategy-outcome pair reveals $\epsilon$ and, with it, the entire mapping of $x$ to $u(y){ }^{1}$

Introducing rugged uncertainty involves changing the functional form of $\epsilon$ so that it varies with $x$. Callander (2011a b ) proposes that a more realistic error function is a path of standard Brownian motion, $B(x)$, scaled by a variance parameter $\sigma$. Thus, $y=1-x+\sigma B(x)$. The Brownian path, $B(x)$, introduces complex uncertainty to the relationship between strategies, $x$, and outcomes, $y$. The scaling parameter, $\sigma$, tunes how much uncertainty there is in the relationship between $x$ and $y$. For low $\sigma, y$ is approximately a linear function of $x$. For high $\sigma$, the uncertainty generated by the Brownian path dominates what is previously known by the organization.

This formulation of a rugged fitness landscape, hereafter abbreviated $\psi(x)$, captures many of the properties of prior modeling techniques, but with one major additional advantage $2^{2}$ Because the statistical properties of standard Brownian motion are well-understood, the actors in the model

\footnotetext{
${ }^{1}$ Once $\epsilon$ is known, the organization knows that $x=1+\epsilon$ will produce the optimal $y=0$.

${ }^{2}$ See Rivkin 2000) for a discussion of the close similarities between NK landscapes and random walks
} 
have well-defined priors about the probability distribution of $y=\psi(x)$, conditional on the history of previously revealed strategy-outcome pairs. As such, search decisions can be endogenously driven by the desire to maximize performance. NK landscapes and fractal landscapes lack easily calculable priors, which makes formal analysis of endogenous models of search considerably more challenging $\mathrm{H}^{3}$

Returning to the example of the master plan for the WTC site, imagine the original Beyer Blinder Belle master plan, $x_{0}=0$, produces an outcome of $y_{0}=1$, where higher values of $y$ represent an stronger emphasis on commercial goals and lower values of $y$ indicate an tilt towards civic goals.' Libeskind's task is to design a new prototype that better aligns with the goals of the project where the ideal outcome is 0 .

Figure 4a, Figure 4b, and Figure 4c decompose the fitness landscape associated with the search for a better design. Figure 4a illustrates the relationship between strategies (plans for the site) and outcomes (commercial vs. civic considerations). The solid line indicates the true functional relationship, $\psi(x)=1-x+B(x)$, which is hidden from Libeskind except for the known status quo at $(0,1)$. (For the purpose of simplicity, I assume that $\sigma=1$ in these illustrations.) The dashed line represents the expected functional relationship, $E[\psi(x)]=1-x$. The dotted lines capture two standard deviations above and below the expected value of $\psi(x)$. The upper bound is $1-x+2 \sqrt{x}$. The lower bound is $1-x-2 \sqrt{x}$. Approximately 95 percent of all realizations of $\psi(x)$ fall within these bounds. Figure $4 \mathrm{~b}$ presents the mapping from outcomes, $y=\psi(x)$, to utility, $u(y)=-y^{2}$. Utility is maximized at $y=0$, which means that organizations seek strategies that produce outcomes near 0 . Figure 4c brings the mapping from strategies to outcomes together with the utility function. In Figure 4c, the solid line represents the true relationship between strategies, $x$, and fitness, $u(\psi(x))$. The utility function combines the smooth, single-peaked characteristics of quadratic-loss utility with the rugged uncertainty of the path of Brownian motion.

\section{[FIGURE 4 GOES ABOUT HERE]}

\footnotetext{
${ }^{3}$ Standard Brownian motion, denoted $B(x)$, is a continuous Gaussian stochastic process with stationary and independent increments such that $B(0)=0, E[B(x)]=0$, and $\operatorname{Cov}\left(B\left(x_{1}\right), B\left(x_{2}\right)\right)=E\left[B\left(x_{1}\right) B\left(x_{2}\right)\right]=\min \left(x_{1}, x_{2}\right)$. Thus, $\operatorname{Var}(B(x))=E\left[B(x)^{2}\right]=x$. The probability distribution of $\sigma B(x)$ conditional on one known strategy-outcome pair at the origin is Normal with mean 0 and variance $|x| \sigma^{2}$. For $x$, between two known strategy-outcome pairs, the distribution of $B(x)$ is defined by the properties of a Brownian bridge that spans the two pairs. For example, assume that two strategy-outcome pairs, $\left(x_{l}, y_{l}\right)$ and $\left(x_{r}, y_{r}\right)$ are known, where $x_{l}<x_{r}$. For all $x<x_{l}, \psi(x)$ is distributed Normal with mean $y_{l}$ and variance $\left|x_{l}-x\right| \sigma^{2}$. For all $x>x_{r}, \psi(x)$ is distributed Normal with mean $y_{r}$ and variance $\left|x_{r}-x\right| \sigma^{2}$. For all $x_{l}<x<x_{r}, \psi(x)$ is distributed Normal with mean $y_{l}+\left(x-x_{l}\right) \frac{y_{r}-y_{l}}{x_{r}-x_{l}}$ and variance $\frac{\left(x_{r}-x\right)\left(x-x_{l}\right)}{x_{r}-x_{l}} \sigma^{2}$. This is all of the information required in order to define the distribution of $\psi(x)$ conditional on previously learned strategy-outcome pairs.
} 


\section{Myopic vs. Hyperopic Experimentation}

The model illustrates the difference between experimentation strategies that focus on maximizing the fitness of the offline outcome, that is, myopic strategies, and those that seek to use the experiment in order to improve performance when the project goes online, that is, hyperopic strategies.

Myopic strategies are risk-averse. They trade-off the desire to achieve an expected outcome close to 0 with the increased uncertainty associated with more distant experimentation Callander, 2011ab). Myopic offline experimentation sacrifices online performance, because it fails to take the dynamic nature of search into account. An offline strategy can be tweaked in the online phase in response to the revealed offline outcome. Because the variance associated with untried strategies is lower between two known strategy-outcome pairs than for strategies outside of the support of previously tried strategies, it is better to more aggressively experiment in the first period and then triangulate in the second.

Figure 5a and Figure 5b illustrate why aggressive experimental search is more desirable for the organization than incremental offline search. The figure contrasts beliefs about online performance conditional on an (incremental) offline strategy of $\frac{1}{4}$ and an (aggressive) offline strategy of $1 \frac{3}{4}$ for $\sigma=1$. For ease of comparison, I assume in both cases that the realized offline outcome is the expected offline outcome. That is, for the incremental strategy, the outcome, $\psi\left(x_{1}=\frac{1}{4}\right)$, is $1-\frac{1}{4}=\frac{3}{4}$. For the aggressive strategy, $\psi\left(x_{1}=1 \frac{3}{4}\right)$ is $1-1 \frac{3}{4}=-\frac{3}{4}$. In Figure 5a, the dotted lines depict two standard deviations above and below the expected online outcome conditional on the incremental offline strategy. The dot-dashed line represents two standard deviations above and below the expected online outcome, conditional on the aggressive offline strategy.

The conditional distribution of the stochastic realization of the fitness landscape that lies between two known strategy-outcome pairs is called a "Brownian bridge." The uncertainty on the bridge is tied-down by the two known points on either side. Therefore, for a strategy a certain distance from a known strategy-outcome pair, the variance in outcomes on a Brownian bridge is smaller than the variance in outcomes when uncertainty is unconstrained. This is why the variance associated with online strategies with expected outcomes near 0 is so much smaller for the aggressive offline experiment than for the incremental offline experiment in Figure 5a, Less uncertainty leads to better expected outcomes. 
Figure 5b plots the expected utility associated with online strategies conditional on the two offline experiments. The gray horizontal line indicates the utility for the organization if the manager retains the offline strategy. Note that for both the incremental and aggressive offline strategies, the optimal online strategy requires an adjustment towards the ideal outcome of 0 . However, the optimal online strategy produces a higher expected utility when the offline strategy is $1 \frac{3}{4}$ than when the offline strategy is $\frac{1}{4}$, represented by the higher peak of the dot-dashed curve than the dotted curve.

\section{[FIGURE 5 GOES ABOUT HERE]}

\section{Managerial Heterogeneity and Career Concerns}

A core question addressed by the model is how offline search behavior changes in the presence of managerial career concerns. Managers learning about the fitness of strategies are simultaneously being evaluated by the organizations for whom they work. Even those managers who would otherwise be motivated by firm performance do not want to be reassigned or fired. These career concerns create an principal-agent problem associated with hyperopic experimentation: organization seek online performance, but managers fear being replaced.

In order to incorporate career concerns into the model, I allow the organization to remove the manager in favor of an inexperienced replacement once the offline outcome is observed. Managers are career-motivated. They would prefer to be retained in the online phase of the project than be replaced. All else being equal, managers share the organization's desire to maximize online performance.

Introducing a threat of replacement also requires that managers are different from each other. Otherwise, the potential replacement would face the same strategic decisions in the online phase as the incumbent. I create heterogeneous managers by decomposing the fitness landscape into a universal component that is common to all managers and an idiosyncratic component that is unique to each manager.

The universal component captures the ways in which managers the the same. For example, managers could have similar educational credentials, years of work experience, or occupational socialization. The idiosyncratic component captures the ways that managers differ. For example, managers may have different problem-solving approaches, prior project experience, or individual tastes. In particular, I assume the deterministic portion of the landscape and the extent of un- 
certainty in the mapping from strategies to outcomes is universal to all managers. The stochastic realization of the Brownian path, in contrast, is manager-specific. I define $\psi_{i}$ as the function that maps strategies to outcomes for manager $i$, where $\psi_{i}(x)=1-x+\sigma B_{i}(x)$ and where $B_{i}(x)$ is independent of $B_{j}(x)$ for $i \neq j$.

Figure $6 \mathrm{a}$ and Figure $6 \mathrm{~b}$ illustrate the fitness landscapes for two potential managers. The first manager, the incumbent represented by the solid line, has the same fitness landscape as in Figure 4a, The second manager, a potential replacement represented by the dashed line, has a different fitness landscape driven by a different realization of the Brownian path. Figure 6a represents the relationship between strategies and outcomes for both managers. Figure 6b captures the relationship between strategies and organizational utility. Note that the utility-maximizing strategy for the incumbent and replacement differs, with strategies near $\frac{1}{2}$ being most desirable for the incumbent and those near $1 \frac{3}{4}$ being most desirable for the replacement.

[FIGURE 6 GOES ABOUT HERE]

Prior to observing the outcome of an offline experiment, each manager's expected performance at the task is equal. Ex ante, the organization is indifferent between inexperienced managers. All managers have strategies that produce the optimal outcome of zero with probability approaching 1. What is hidden from the organization and manager is the realization of the stochastic component in the map between strategies and outcomes, i.e., the manager-specific Brownian path. Some managers' Brownian paths remain near its expectation of 0 . For these managers, the cognitive representation of the relationship between strategies and outcomes closely reflects reality. It is easy for these managers to select a strategy that produces a desirable organizational outcome. Other managers' Brownian paths depart from 0 quickly and erratically. These managers face a more difficult search problem, because errors in these managers' cognitive representations lead them to mistakenly choose low performing strategies.

Once the outcome of an offline experiment has been observed, however, the additional information about the incumbent manager differentiates the incumbent from potential replacements. The offline experiment reveals one point in the initial manager's Brownian path. For many managers, the associated reduction in the variance in the mapping from strategies to outcomes makes the incumbent more desirable. However, the offline outcome can also reveal that initial manager is unlikely to produce a successful online outcome, in which case the organization would do better to 
bring on a replacement.

The fact that organizations are learning about managers while managers learn from experience distinguishes this model from prior work. Given enough time, incremental search followed by triangulation once the observed outcome falls below 0 would lead to outcome very close to the ideal. What differentiates managers is not their capacity to produce good outcomes, but the amount of time required to find them.

Prior principal-agent models of managerial decision making generally incorporate either managerial heterogeneity or learning from experience, but not both. For example, Manso (2011) examines a bandit model in which costly search and fears of bad outcomes drive agent behavior. Risk of replacement in that model help to align the preferences of the agent with the principal, but do not reflect agent heterogeneity. Aghion and Jackson (2014) is more similar to this model, because agent search behavior is driven by fears being revealed to be incompetent. In their model, however, the expected payoffs conditional on agent type are fixed. No amount of experience will turn an low performing agent into a high performing one.

\section{Information, Evaluation, and Organizational Commitment}

Career concerns link the manager's offline strategy to the way that offline outcomes are evaluated by the organization. In my model, I explore two considerations that impact the organization's replacement decision. The first is whether the organization can pre-commit to a set of offline outcomes for which it will replace the manager, which I refer to as a "replacement rule." The second is whether the organization can observe both the offline strategy and outcome or instead is only able to observe the offline outcome.

Career-concerned managers undertake offline experiments that minimize their probability of replacement rather than those that maximize performance in the online phase. If the organization cannot commit to a replacement rule, the manager will select the offline strategy that maximizes the chance that the incumbent's online outcome will be marginally more desirable than an inexperienced replacement's online outcome.

If the organization can commit to a replacement rule, the organization will use the either threat of replacement or commitment to retention to align the manager's preferences with the organization's. If organization commits to retain the manager, the manager will choose the offline 
strategy that maximizes the expected performance of the online outcome. However, in committing to retain the manager, the organization foregoes the option to replace a poor performer. Manso (2011) describes this as the problem of excessive continuation.

In contrast, the organization can commit to a set of offline outcomes for which it will replace the manager. This replacement region is calibrated so that the offline experiment that produces the minimum probability of replacement for the incumbent manager also produces a desirable online outcome for the organization. In this case, the organization will sometimes commit itself to replacing a manager whose expected online performance exceeds an inexperienced replacement's. Manso (2011) describes this as the problem of excessive termination.

The second key factor is whether the organization can observe the offline strategy. Sometimes, observing a manager's strategy or inferring a manager's strategy from an offline outcome is easy. When a bartender pours a cocktail, for example, the ingredients are easily observed by patrons. However, strategies are more commonly tacit. In cases where strategic inputs are hard to observe directly or in which understanding the relationship between strategies and outcomes requires expertise, organizations are left making replacement decisions based only on observed outcomes. Upon tasting a glass of wine, for example, it is difficult to infer the cultivation techniques used by the vintner.

I present results from the model under the following five conditions:

1. Observable strategy with organizational commitment. The organization can entirely align the incentives of the manager with the organization's preferences by forcing the manager to undertake the organization's most desired offline experiment.

2. Observable strategy without commitment. The manager chooses the offline strategy that minimizes the likelihood of replacement, with the knowledge that both the offline strategy and outcome are observed by the organization.

3. Tacit strategy without commitment. The manager selects the offline strategy that minimizes the likelihood of replacement, with the knowledge that the organization will infer the offline strategy from the observed outcome. The organization decides whether to retain or replace the manager after inferring the manager's expected strategy. 
4. Tacit strategy with commitment and a tenure guarantee. The organization guarantees that the manager will be retained in the online phase.

5. Tacit strategy with commitment and no tenure guarantee. The organization aligns the manager's preferences with the organization's by selecting a set of offline outcomes for which it will replace the manager.

I show that an observable strategy combined with organizational commitment allows the organization to achieve its first-best outcome. However, if the organization cannot commit, the manager selects an offline strategy that is undesirably blue-sky. I show that no equilibria exist if strategies are tacit and the organization cannot pre-commit to a replacement rule. Finally, I show that if strategies are tacit and organizations can commit to replacement regimes, a tenure guarantee is more desirable for the organization for more uncertain task environments and organizational control is more desirable when facing less uncertain ones.

\section{Model Summary}

An organization delegates a project to a manager. Managers transform strategies, $x \in \mathbb{R}$, into outcomes, $y \in \mathbb{R}$, via a function, $\psi_{i}$, where $i$ indexes managers. $\psi_{i}(x)$ is the sum of a linear function, $1-x$, and a manager-specific stochastic process defined by a realized path of scaled standard Brownian motion, denoted $\sigma B_{i}(x) . \psi_{i}(x)=1-x+\sigma B_{i}(x)$. Utility for the organization is quadraticloss relative to an ideal outcome of $0, u(y)=-y^{2}$. As such, the organization is risk-averse. By the mean-variance decomposition of expected utility under quadratic loss, $E[u(y)]=-E(y)^{2}-\operatorname{Var}(y) \bigsqcup^{4}$

The status quo strategy, $x_{0}=0$, produces a known outcome, $y_{0}=1$, and utility, $u\left(y_{0}\right)=-1$, for the organization. A positive increment in $x$ will move the organizations towards its ideal outcome of 0 in expectation.

The model begins in the offline phase with the organization selecting an initial manager $(i=1)$. This manager has the opportunity to experiment with an offline strategy, $x_{1}$, and observe an offline outcome, $y_{1}=\psi_{1}\left(x_{1}\right)$. In the online phase, the organization then decides whether to retain the incumbent or to replace them with a replacement $(i=2)$. The selected manager implements an

\footnotetext{
${ }^{4}$ In the appendix, I demonstrate how strategies and outcomes generated from the parameterization $\psi_{i}(x)=$ $1-x+\sigma B_{i}(x)$ can be straightforwardly generalized to $f_{i}(x)=\alpha+\mu x+\sigma B_{i}(x)$, where $\alpha>0$ and $\mu<0$, as in Callander (2011a b).
} 
online strategy, $x_{2}$, which produces an online outcome $y_{2}=\psi_{i}\left(x_{2}\right)$, where $i=1$ if the incumbent is retained and $i=2$ if the incumbent is replaced. The organization's payoff is $-\left(y_{2}\right)^{2}$.

Managers are tenure-motivated. First and foremost, they desire to be retained. Secondarily, they have preferences that align with the organization's. As such, the initial manager's choice of offline strategy is determined by the rubric the organization uses to determine whether the experiment was a success or failure. Following the offline phase and the replacement decision by the organization, however, both the incumbent and replacement choose the online strategy that maximizes expected utility for the organization.

Replacement decisions depend on two key features of the model. The first is whether both the offline strategy and outcome are observable to the organization. If both are observable, I describe the offline strategy as observable; if just the outcome is observable, I describe the offline strategy as tacit. The second is whether the organization can commit to a replacement rule prior to the initial manager selecting an offline strategy. If the organization cannot commit, then it replaces the incumbent whenever a replacement is at least as desirable as the incumbent. If the organization can commit, then it may retain an undesirable incumbent manager or replace a desirable one in order to induce a more effective offline experiment.

I define tie-breaking rules, for ease of formal exposition. When choosing between two strategies, $x_{i}$ and $x_{j}$ where $x_{i}<x_{j}$, that produce the same expected utility, the organization prefers the strategy that produces an expected outcome closer to 0 . If $x_{i}$ and $x_{j}$ produce outcomes with the same expected outcome, then the organization prefers $x_{i}$. I also assume that when selecting between the incumbent and a replacement that produce the same expected utility, the organization replaces the incumbent.

\section{Equilibrium Strategies and Comparative Statics}

I find Nash equilibrium strategies for the organization and managers. As is common in rational actor models of this sort, I assume that organizations and managers seek to maximize utility, subject to rational beliefs about the strategies of other actors in the game. I also assume that organizations update their beliefs about the incumbent manager's future strategy conditional on the history of revealed strategy-outcome pairs (Fudenberg and Tirole, 1991).

I find equilibrium strategies using backwards induction. First, I examine the behavior for man- 
agers in the online phase conditional on the outcomes in the offline phase. Then, I characterize replacement decisions for the organization. Finally, I determine equilibrium offline strategies for managers conditional on the organization's replacement decisions. I denote equilibrium offline strategies as $x_{1}^{*}$. In the text of the paper, I emphasize the intuition behind the results derived in the model. However, analytic proofs and annotated computer code used to find computational solutions is included in the technical appendix.

\section{Online Strategy}

Following the organization's replacement decision, the selected manager chooses the online strategy that maximizes expected utility for the organization. In the online phase, the manager does not fear replacement. Equilibrium strategies and organizational outcomes, therefore, are equivalent to the myopic search strategies derived in Callander (2011a b).

I begin by describing the optimal online strategy for the replacement manager. Because online strategies more distant from the known status quo induce greater variance in outcomes, riskaversion leads the replacement to search incrementally, if at all. For sufficiently high uncertainty, i.e., for high $\sigma$, the risks associated with incremental exploration from the known status quo exceed expected benefits, so the replacement retains the status quo strategy. Specifically, if $\sigma \geq \sqrt{2}$, the replacement selects an online strategy of 0 . For $\sigma<\sqrt{2}$, the replacement selects an online strategy

with an expected outcome equal to $\frac{\sigma^{2}}{2}$, which is between the status quo of 1 and ideal outcome of 0.

The optimal online strategy for the incumbent manager depends on the offline strategy and outcome. There are four types of online strategies that the incumbent manager can implement after observing the offline strategy and outcome: (1) implement $x_{1},(2)$ explore outside of the support of prior experience, (3) triangulate between known strategy-outcome pairs, or (4) backslide to $x_{0}$ :

1. Implement $x_{1}$ : If the offline outcome is sufficiently close to the ideal outcome of 0 , the incumbent will retain the offline strategy in the online phase. Returning to the WTC site example, if Libeskind offered a proposal that satisfied the goals of the LMDC and Silverstein, there would be no further revision.

2. Explore outside of the support of prior experience: If the offline outcome is greater than 0 
(but not too much greater than 0), the incumbent selects an online strategy that exceeds the offline strategy in order to produce an expected online outcome closer to 0. Figure 5b demonstrates the benefits of this type of online search. For the incremental offline strategyoutcome pair, $\left(\frac{1}{4}, \frac{3}{4}\right)$, the online strategy that produces the highest expected utility is greater than $\frac{1}{4}$. For example, if Libeskind produced a plan that was too biased towards commercial goals, he could revise the plan to make it even more civic-minded in the online phase.

3. Triangulate between known strategy-outcome pairs: If the offline outcome is sufficiently less than 0 , the incumbent selects an online strategy between 0 and the offline strategy. Focusing now on the aggressive offline strategy-outcome pair, $\left(1 \frac{3}{4},-\frac{3}{4}\right)$, in Figure $5 \mathrm{~b}$, the online strategy that produces the highest expected utility falls between 0 and $1 \frac{3}{4}$. This was the actual outcome of the WTC master plan. As Libeskind's proposal was too biased towards civic goals, the final plan triangulated between the proposal and the status quo in the online phase.

4. Backslide to $x_{0}$ : When the offline outcome is sufficiently undesirable, the incumbent will backslide to the status quo strategy in the online phase. There are two types of offline outcomes that produce backsliding. The first are offline outcomes that are expected to be less than the status quo outcome of 1 , but instead are (considerably) higher than 1 . In this case, the offline strategy produces on outcome that is even less desirable than the status quo. Searching for online strategies associated with outcomes near 0 thus require large and uncertain changes to the offline strategy. For example, if Libeskind's proposal was even more commercially-minded than the status quo, he could conclude that retaining status quo is the best he can do. The second type of offline outcome that leads to backsliding is expected to be very negative, but instead is only modestly negative. This leads to a shallow slope on the Brownian bridge connecting the status quo and the offline experiment. On shallow Brownian bridges, incremental changes to strategies with known outcomes produce small changes in expected outcomes at the cost of outsized increases in the uncertainty associated with those outcomes. For example, if Libeskind attempted to be extremely civic-minded with his plan, but returned a proposal that was perceived as only modestly civic-minded, his capacity to effectively triangulate would be severely hampered by the high uncertainty associated with untried strategies. If variability in outcomes associated with strategies between the status 
quo and offline strategy were sufficiently high (and the status quo were more desirable than the offline outcome) he'd prefer the status quo to any untried strategy.

Figure 7a and Figure 7b illustrate optimal online strategies conditional on offline strategies and offline outcomes for $\sigma=1$ and $\sigma=2$, respectively. The regions in which the incumbent selects the four different types of online strategies are indicated by the solid lines in the figures. The regions are overlaid on top of the expected relationship between offline strategies and outcomesrepresented by the dashed gray line - as well as one, two, and three standard deviations above and below the expected outcomes - represented by the dotted gray lines. Approximately 99 percent of offline outcomes fall within three standard deviations of the expected offline outcome. Note that offline strategies with expected outcomes greater than 1 are unlikely to provide much information that is useful in the online phase. For these offline strategies, the incumbent's online strategy will most often be exploration outside the support of experience in an effort to find an outcome closer to 0 than the status quo.

Driving the major differences between Figure $7 \mathrm{a}$ and Figure $7 \mathrm{~b}$ are decisions about whether to continue to search for outcomes near 1 . When uncertainty is higher, the organization prefers a known strategy-outcome pair to risky experimentation. If $\sigma=1$, the incumbent manager will therefore continue to explore in the online phase in an effort to achieve an outcome closer to 0 . If $\sigma=2$, in contrast, the increased uncertainty leads the incumbent to backslide to the status quo or retain the offline strategy in the online phase.

[FIGURE 7 GOES ABOUT HERE]

Offline Strategies and Replacement Decisions

Next, I examine offline strategies and organizational replacement decisions for each of the five conditions.

\section{Observable Strategy with Commitment}

If the organization can observe the offline strategy and can pre-commit to a set of offline strategy-offline outcome pairs for which it will replace the incumbent manager, then it can induce the first-best offline strategy with the following rule: If the initial manager selects any offline strategy other than what it best for the organization, replace the manager. If the organization's 
expected utility if it replaces the incumbent is greater than or equal to the organization's expected utility if it retains the incumbent, replace the manager.

Finding the equilibrium offline strategy for the manager and the optimal replacement rule for the organization is equivalent to finding the optimal offline strategy and replacement rule in the absence of a principal-agent problem. The non-convex, piecewise nature of the optimal online strategy conditional on the offline strategy and outcome complicates analytic solutions for the equilibrium offline strategy and replacement rule. Therefore, I use genetic optimization to find equilibrium solutions conditional on $\sigma$. Prior work shows that for unidimensional global optimization of nonconvex functions, genetic optimization performs quite well (Mebane Jr. and Sekhon, 2011). In general, I report equilibria for $\sigma \in\left[\frac{1}{5}, 3\right]$, which I believe to be sufficient to characterize the range of interesting outcomes in the model.

Figure 8 plots the equilibrium offline strategy, $x_{1}^{*}$, for a range of uncertainty levels. In low uncertainty environments, the equilibrium strategy overshoots the optimal outcome of 0 in expectation, which reflects the desirability of online search within the support of prior experience. However, in higher uncertainty environments, the manager moderates its offline experiment in response to fears of uncertain offline outcomes. This trade-off between the desire to triangulate between known strategy-outcome pairs and the higher variance associated with more aggressive search determines offline behavior when managers and organizations have aligned preferences. Because this set of conditions - observable strategy and commitment - allows for first-best outcomes, the equilibrium offline strategy in Figure 8 is the baseline against which I compare other results in the model.

\section{[FIGURE 8 GOES ABOUT HERE]}

The equilibrium offline strategy does not guarantee that the incumbent manager is retained by the organization. After observing the offline experiment and offline outcome, there are two potential ranges of $y_{1}$ for which the organization prefers a replacement to the incumbent. The first is any offline outcome greater than 1 . In this case, the incumbent's online strategy will either involve backsliding to the status quo or exploring outside of the support of experience from a known strategy-outcome pair more distant from the optimal outcome than the status quo is. I will often refer to this range as the upper replacement region. In the WTC case, these outcomes represent plans that are even more commercially-minded than the Beyer Blinder Belle proposal. Silverstein and the LMDC would conclude that the incumbent architect is a worse fit for the online phase than 
a new architect.

The organization also replaces the incumbent manager for outcomes that produce an undesirably shallow Brownian bridge between the status quo and offline strategy-outcome pair. I refer to this range as the lower replacement region. It the WTC case, this occurs if the architect sought to be very civic-minded, but ended up with a plan that only had a modest civic bias. In this case, incremental changes to strategies with known outcomes for the incumbent will generate even more outcome uncertainty than equivalent changes for a replacement.

Figure 9a and Figure 9b display the offline strategy-offline outcome pairs for which the manager is replaced by the organization for $\sigma=1$ and $\sigma=2$, respectively. They also include the expected offline outcome associated with offline strategies, indicated by the dashed line, and one, two, and three standard deviations above and below the expected offline outcome, indicated by the gray dotted lines.

\section{[FIGURE 9 GOES ABOUT HERE]}

For high levels of uncertainty, i.e., $\sigma \geq \sqrt{2}$, the lower replacement region is the same as the region for which the incumbent backslides to the status quo strategy for offline outcomes less than 0 . The minimum offline strategy for which this region exists is $\frac{\sigma^{2}}{4}$, which is considerably larger than the equilibrium offline strategy for such high uncertainty. As such, in equilibrium the organization only replaces the manager if the offline outcome exceeds 1. For lower levels of uncertainty, i.e., $\sigma<\sqrt{2}$, the lower replacement region is strictly larger than the region in which the incumbent backslides to the status quo, because the expected utility from a replacement's online outcome exceeds the utility from the status quo. The minimum offline strategy for which a lower replacement region exists for $\sigma<\sqrt{2}$ is $4-\sigma^{2}$. This still exceeds the equilibrium offline strategy. As such, for all levels of uncertainty, the organization replaces the incumbent in equilibrium if and only if the offline outcome is greater than or equal to 1.

\section{Observable Strategy with No Commitment}

If the organization cannot commit to a replacement rule, the initial manager selects the offline experiment with the lowest probability of replacement instead of the one that maximizes expected online performance for the organization. The manager will never select an offline strategy that is less than the minimum strategy for which there exists a lower replacement region. To illustrate 
why, let $\sigma=1$ and assume the manager is considering two offline strategies: $x_{1}=1$ and $x_{1}=3$. As depicted in Figure 9a, the upper replacement region captures any offline outcome greater than or equal to 1 . The minimum offline strategy for which there is a lower replacement region is 3 . If the manager chooses an offline strategy of 1 , then there is approximately a 16 percent chance the offline outcome will exceed 1 and the manager will be replaced. An offline strategy of 3, in contrast, has to an approximately 1 percent chance of exceeding 1 . Thus, the manager will choose $x_{1}=3$ instead of $x_{1}=1$.

Whether the minimum strategy for which there is exists a lower replacement region represents the equilibrium offline strategy depends on whether the probability that an offline outcome falls in the lower replacement region grows faster than the probability that an offline outcome falls in the upper replacement region declines. Otherwise, unboundedly large offline strategies could generate the lowest probability of replacement. Figure 10a and Figure 10b show the probabilities of replacement for the initial manager conditional on the chosen offline strategy for $\sigma=1$ and $\sigma=2$. Note the sharp elbow in both curves at the minimum offline strategy for which there exists a lower replacement region. Thus, the equilibrium offline strategy for $\sigma=1$ is 3 and for $\sigma=2$ is 1 . This considerably exceeds what is most desirable from the perspective of the organization.

[FIGURE 10 GOES ABOUT HERE]

Figure 11 compares equilibrium offline strategies when strategies are observable and the organization cannot commit to a replacement rule (solid line) against when strategies are observable and the organization can commit (dashed line). When the organization cannot pre-commit, equilibrium offline strategies are much larger than when it can. If the manager fears the career consequences of a bad offline outcome, a manager will choose an offline strategy that is blue-sky in an effort to avoid revealing itself as undesirable. This drives the principal-agent problems associated with hyperopic experimentation.

\section{[FIGURE 11 GOES ABOUT HERE]}

\section{Tacit Strategy with No Commitment}

If the organization cannot observe the offline strategy, then determining whether the incumbent is more desirable than a replacement is more complicated. The organization is now forced to make inferences about the offline strategy from the observed offline outcome, and then, based on those probabilities, choose whether or not to retain the incumbent. 
In fact, the difficulty of inferring strategies from observed outcomes means that no equilibrium exists if strategies are tacit and the organization cannot pre-commit. To see why, note that for any finite lower bound of the lower replacement region, the manager can always minimize its probability of replacement with a sufficiently large increase in its offline strategy 5

If the organization believes the offline strategy to be infinite, however, it would respond with a lower replacement region that encompasses all outcomes less than or equal to $-\sqrt{\left(1-\frac{\sigma^{2}}{4}\right) \sigma^{2}}$ for $\sigma<\sqrt{2}$ or -1 for $\sigma \geq \sqrt{2}$, which is the boundary at which the organization is indifferent between the incumbent retaining its offline strategy and removing the incumbent in favor of an inexperienced replacement. In response, the manager would select a finite offline strategy to decrease the probability of replacement. Knowing that the manager's offline strategy is finite, the organization would then respond with a replacement rule that either contains no lower replacement region or one with a finite lower bound. This generates a contradiction, as no equilibrium can exist that includes a lower bound to the lower replacement region.

\section{Tacit Strategy with Commitment: Guaranteed Tenure}

The non-existence of equilibria with tacit strategies likely contributes to the ubiquity of wellworn norms and rules in organizations that govern offline experimentation. The next section of the analysis examines what types of rules produce effective offline experimentation when offline strategies are tacit.

The most straightforward way to align the preferences of the manager with the organization's is to guarantee the initial manager is retained, regardless of the offline outcome. This guarantee does not come free to the organization, as the organization now foregoes the possibility of replacing an undesirable incumbent. Retaining incumbent managers following offline outcomes greater than 1 is especially costly for the organization.

In response, in low uncertainty environments, i.e., $\sigma<\sqrt{2}$, the manager chooses an offline strategy that is more extreme than would otherwise be desirable in order to mitigate the likelihood of this bad outcome. In high uncertainty environments, however, both the incumbent and inexperienced replacement retain the status quo if the offline strategy is greater than 1 . Therefore, if

\footnotetext{
${ }^{5}$ This follows from the fact that the standard deviation of the distribution of potential outcomes from offline strategies grows at a rate equal to the square-root of the offline strategy.
} 
$\sigma \geq \sqrt{2}$, a tenure guarantee produces the first-best organizational outcome for the organization.

Figure 12 compares the equilibrium offline strategy under guaranteed tenure to the equilibrium strategy if strategies are observable and the organization can pre-commit. The vertical gray line indicates $\sigma=\sqrt{2}$. The equilibrium strategy under a tenure guarantee is too large for levels of uncertainty to the left of the line, because organizations are unable to replace incumbent managers with offline outcomes greater than 1.

[FIGURE 12 GOES ABOUT HERE]

\section{Tacit Strategy with Commitment: Outcome-based Replacement}

In contrast, the organization can commit a range of outcomes for which it retains incumbents and replace those whose offline outcomes fall outside of the range. Whereas guaranteed tenure aligns the preferences of managers and organizations by providing managers greater freedom, outcomebased replacement achieves the same end through greater organizational control.

The cost of outcome-based replacement is that the organization must commit to a lower replacement region in order to induce desirable offline search. However, the offline strategies the organization seeks to induce are more modest than the minimum offline strategy for which organizations prefer to replace incumbents for offline outcomes less than 0 . This leads to excessive replacement.

I focus on replacement rules for which the set of offline outcomes for which the organization retains the manager is a continuous segment of the set of potential offline outcomes. I fix the upper bound of the set of acceptable outcomes to be 1 (not inclusive), as any offline outcome between 0 and 1 makes the incumbent more desirable than the replacement. The lower bound of the range of acceptable outcomes is set so that the best response of the manager produces the highest expected utility for the organization $\sqrt[6]{ }$

Figure 13 compares the equilibrium offline strategy under an outcome-based replacement rule to the first-best strategy. The solid line indicates the equilibrium offline strategy under outcome-based replacement. The dashed line represents the equilibrium offline strategy if strategies are observable and the organization can commit to a replacement rule. Note that the offline strategies here are considerably closer to the first-best strategy for the organization than the offline strategies were

\footnotetext{
${ }^{6}$ It is possible that there are other replacement regions that generate higher expected utility for the organization. Putting aside the practical difficulties of implementing more complex rules, the results presented here serve as a lower bound of the performance of outcome-based rules.
} 
under a tenure guarantee.

\section{[FIGURE 13 GOES ABOUT HERE]}

Both of these approaches lead to an offline experiment roughly in line with what is desired by the organization. However, both replacement regimes also bring inefficiencies. For guaranteed tenure, excessive continuation occurs because organizations cannot replace managers who are unlikely to perform well when the project goes online. Outcome-based replacement faces the opposite problem: excessive termination occurs because the organization is forced to replace managers who are likely to perform better than the replacement when the project goes online. Figure 14 demonstrates the extent to which the inefficiencies caused by both rules reduce the organization's expected utility. The solid line represents the expected utility loss associated with a tenure guarantee relative to the first-best offline strategy from the perspective of the organization. The dashed line captures the utility loss associated with outcome-based replacement.

\section{[FIGURE 14 GOES ABOUT HERE]}

For low uncertainty task environments, i.e., low $\sigma$, outcome-based replacement performs better. The cost of being forced to retain an undesirable incumbent outweighs the possibility of replacing a desirable one. This is because replacements produce desirable online outcomes when $\sigma$ is low. Less is gained through the incumbent's opportunity to experiment offline. As uncertainty increases

towards $\sqrt{2}$, guaranteed tenure becomes more desirable. Replacements produce worse outcomes in more uncertain environments, reducing the relative cost of the tenure guarantee. For $\sigma \geq \sqrt{2}$, the expected utility under the tenure guarantee equals expected utility under aligned preferences and, as a result, produces the optimal outcome for the organization.

\section{Discussion}

Offline experiments are one way that organizations try to promote risky search. However, the conflicting motivations of managers may sap these experiments of their informational value. Career concerns of managers, in particular, can lead to over-exploratory, blue-sky experimentation. The paper explores how career concerns impact offline experimentation using a novel model of search over rugged landscapes.

To my knowledge, this is the first formal model in which organizations learn about managerial quality while managers learn from experience. In the model, each manager contributes a unique 
stochastic component to the functional relationship between strategies and outcomes. Organizations prefer managers whose beliefs about the mapping from strategies to outcomes closely reflect reality. These managers are better able to find strategies that produce outcomes that are desirable for the organization. Organizations evaluate managers based on the outcomes of their offline experiments. For sufficiently bad offline outcomes, the organization will remove the incumbent in favor of an inexperienced replacement. Managers in turn pervert their offline experiments in order to minimize the probability they are replaced.

I present the model as an intra-organizational interaction, but it also applies straightforwardly to many inter-organizational relationships. Firms often hire consultants to help with change management. The consultant begins with a pilot, which is then presented to management as a model for organizational change. If management is unhappy the results of the pilot, the consulting firm will be replaced and a large contract lost. Government agencies often contract with social sector organizations for new public initiatives, especially in international development. These organizations have to conduct randomized control trials in order to demonstrate the validity of their approach prior to receiving the larger contract. Despite the existence of an organizational boundary, in these settings the same worries about revealed competence and repeat business apply.

The paper brings together the approaches to modeling search behavior in organizational theory and organizational economics. Questions related to search and learning in organizations have long been central to both fields. However, the overriding emphasis on decision-making complexity in organization theory has prevented game theoretic treatments of inter-organizational interactions. In organizational and political economics, in contrast, the focus on intra-organizational conflict and rational action have precluded realistic models of decision-making in the face of uncertainty. The modeling approach developed in Callander (2011a b) offers an opportunity to tie together these two literatures that, to this point, have passed each other in the night.

Integrating these paradigms for modeling organizational search and learning constrains the types of questions that can be addressed by the analyst relative to the simulation-based models of experiential learning common in organizational theory. Game theory is a powerful tool for modeling intra-organizational dynamics, but it restricts the questions that can be answered to those amenable to equilibrium analysis. Moreover, economic modeling gives preference to equilibria that can be solved analytically, which allows the analyst to derive closed-form comparative statics and 
demonstrate the global scope of solutions. Analytic solutions also offer a higher level of transparency than computationally-solved games.

The evolutionary approach common to organization-theoretic models of search faces the opposite challenge. These models assume a rule that drives search for each actor, then examine how the search rule interacts with complexity in the task environment to produce organizational performance. Search rules reflect assumptions grounded in prior behavioral research, rather than emerging endogenously from goals of the actors the model.

This paper brings together the best of both modeling approaches. Actor behavior in the model is based on equilibrium solutions to a dynamic game. By relying on an analytically tractable source of uncertainty and a limited series of decisions, the model is characterized by a manageable set of key assumptions about of actor preferences, uncertainty, information transparency, and organizational control. Although the dynamic nature of the model requires computation to solve, the results of the universe of interesting combinations of parameters and assumptions can be transparently presented.

This paper is an example of the potential payoffs to the study of strategic management and organizational learning when these two modeling approaches are combined. Existing theory on organizational search emphasizes how risk aversion produces undesirable incrementalism. Past literature examining managerial career concerns points in the same direction. Yet, in offline experiments, we often observe the opposite problem: managers seek outcomes so extreme as to be incapable of being integrated online. This paper both explains why and offers recommendations for what organizations can do about it.

Managers that fear the career implications of failed experiments engage in overly aggressive offline search to minimize the probability they are revealed to be a poor fit to take the project online. If strategies are observable and the organization can commit to a rubric that it will use to evaluate and replace managers, then this agency problem can be straightforwardly resolved. Yet, in most contexts, this is not possible. Strategies are often tacit. Information about offline strategies risks being strategically manipulated by managers so that outcomes appear in a better light.

For strategies that are tacit and tasks that face sufficiently high uncertainty, alleviating career concerns by offering a tenure guarantee is costless for the organization. However, for lower uncertainty tasks, there are no replacement rules that entirely resolve the agency problem. If the 
organization commits to retaining an incumbent manager, then it risks being stuck with a bad manager when the project goes online. If the organization commits to a set of outcomes for which it will replace a manager, then it forces itself to remove incumbents who are expected to perform better than replacements.

The conclusions derived from the model agree with human resource practices common to many successful firms. For low uncertainty tasks, the control offered by outcome-based replacement promotes more effective offline search. For higher uncertainty tasks, in contrast, it is more important to give managers the freedom to make mistakes. However, the rationale for these practices in motivating effective offline search proposed here differs from common justifications offered in the online context. Prior models advise outcome-based replacement as a remedy for managerial shirking and tenure guarantees as a remedy for uncertainty-driven incrementalism (Manso, 2011). This model instead points to the trade-offs associated with human resources practices that address the problem of blue-sky experimentation driven by career concerns. In so doing, the model contributes to our understanding of some of the the management practices that drive great organizations. 


\section{References}

Aghion, P. and Jackson, M. (2014). Inducing Leaders to Take Risky Decisions: Dismissal, Tenure, and Term Limits. National Bureau of Economic Research Working Paper Series, No. 20301.

Anderson, P. and Tushman, M. L. (1990). Technological Discontinuities and Dominant Designs: A Cyclical Model of Technological Change. Administrative Science Quarterly, pages 604-633.

Arthur, R. (2016). The New Science Of Hitting.

Bendor, J. and Meirowitz, A. (2004). Spatial Models of Delegation. American Political Science Review, 98(2):293-310.

Beshears, J. and Gino, F. (2014). Experiment with Organizational Change Before Going All In. HBR.org.

Callander, S. (2008). A Theory of Policy Expertise. Quarterly Journal of Political Science, 3(2):123140.

Callander, S. (2011a). Searching and Learning by Trial and Error. American Economic Review, 101:2277-2308.

Callander, S. (2011b). Searching for Good Policies. American Political Science Review, 105(4):643662.

Callander, S. and Matouschek, N. (2014). Managing on Rugged Landscapes. Working Paper.

Canes-Wrone, B., Herron, M. C., and Shotts, K. W. (2001). Leadership and Pandering: A Theory of Executive Policymaking. American Journal of Political Science, 45(3):532-550.

Collins, H. (2010). Tacit and Explicit Knowledge. University of Chicago Press, Chicago.

Crawford, V. P. and Sobel, J. (1982). Strategic Information Transmission. Econometrica: Journal of the Econometric Society, 50(6):1431-1451.

Csaszar, F. A. and Eggers, J. P. (2013). Organizational Decision Making: An Information Aggregation View. Management Science, 59(10):2257-2277.

Csaszar, F. A. and Levinthal, D. A. (2016). Mental Representation and the Discovery of New Strategies. Strategic Management Journal.

Cyert, R. M. and March, J. G. (1963). A Behavioral Theory of the Firm. Blackwell, Cambridge, 2nd edition.

Davis, J. P., Eisenhardt, K. M., and Bingham, C. B. (2007). Developing Theory through Simulation Methods. Academy of Management Review, 32(2):480-499.

Dichtler, S. F., Gagnon, C., and Alexander, A. (1993). Leading organizational transformations. McKinsey Quarterly.

DiMaggio, P. J. and Powell, W. W. (1983). The Iron Cage Revisited: Institutional Isomorphism and Collective Rationality in Organizational Fields. American Sociological Review, 48(2):147-160.

Fleming, L. (2002). Finding the Organizational Sources of Technological Breakthroughs: The Story of Hewlett Packard's Thermal Ink Jet. Industrial and Corporate Change, 11(5):1059-1084. 
Fleming, L. and Sorenson, O. (2004). Science as a Map in Technological Search. Strategic Management Journal, 25:909-928.

Forgey, B. (2002). Building Blocks for the World Trade Center Site; Push to Make Quick Choices Threatens To Create Uninspired Architecture. Washington Post.

Fudenberg, D. and Tirole, J. (1991). Game Theory. MIT Press, Cambridge.

Ganz, S. C. (2018). Ignorant Decision Making and Educated Inertia: Some Political Pathologies of Organizational Learning. Organization Science, 29(1):39-57.

Gavetti, G. and Levinthal, D. (2000). Looking Forward and Looking Backward: Cognitive and Experiential Search. Administrative Science Quarterly, 45(1):113-137.

Gavetti, G., Levinthal, D. A., and Rivkin, J. W. (2005). Strategy making in novel and complex worlds: the power of analogy. Strategic Management Journal, 26(8):691-712.

Gertner, J. (2012). The Idea Factory: Bell Labs and the Great Age of American Innovation. The Penguin Press, New York.

Gibbons, R., Matouschek, N., and Roberts, J. (2012). Decisions in Organizations. In Gibbons, R. and Roberts, J., editors, The Handbook of Organizational Economics, pages 373-431. Princeton University Press, Princeton.

Gibbons, R. and Roberts, J. (2012). Economic Theories of Incentives in Organizations. In Gibbons, R. and Roberts, J., editors, The Handbook of Organizational Economics, pages 56-99. Princeton University Press, Princeton.

Gilligan, T. W. and Krehbiel, K. (1987). Collective Decisionmaking and Standing Committees: An Informational Rationale for Restrictive Amendment Procedures. Journal of Law, Economics, E Organization, 3(2):287-335.

Gilligan, T. W. and Krehbiel, K. (1989). Asymmetric Information and Legislative Rules with a Heterogeneous Committee. American Journal of Political Science, 33(2):459-490.

Goldberger, P. (2005). Up from Zero: Politics, Architecture, and the Rebuilding of New York. Random House, New York, NY.

Hamel, G. and Spence, S. (2010). Innovation Democracy: W.L. Gore's Original Management Model. Management Innovation Exchange.

Hannan, M. T. and Freeman, J. (1984). Structural Inertia and Organizational Change. American Sociological Review, 49(2):149-164.

Holmstrom, B. (1999). Managerial Incentive Problems: A Dynamic Perspective. The Review of Economic Studies, 66(1):169-182.

Holmstrom, B. and Ricart i Costa, J. (1986). Managerial Incentives and Capital Management. Quarterly Journal of Economics, 101(4):835-860.

Kelley, T. and Littman, J. (2001). The Art of Innovation: Lessons in Creativity from IDEO, America's Leading Design Firm. Currency/Doubleday, New York. 
Kogut, B. and Zander, U. (1992). Knowledge of the Firm, Combinative Capabilities, and the Replication of Technology. Organization Science, 3(3):383-397.

Lashinsky, A. (2006). Chaos By Design. Fortune.

Lee, S. and Meyer-Doyle, P. (2017). How Performance Incentives Shape Individual Exploration and Exploitation: Evidence from Microdata. Organization Science, 28(1):19-38.

Levinthal, D. A. (1997). Adaptation on Rugged Landscapes. Management Science, 43(7):934-950.

Levinthal, D. A. and Warglien, M. (1999). Landscape Design: Designing for Local Action in Complex Worlds. Organization Science, 10(3):342-357.

Levitt, B. and March, J. G. (1988). Organizational learning. Annual review of sociology, pages 319-340.

Lindbergh, B. and Miller, S. (2016). The Only Rule Is It Has To Work. Henry Holt and Co., New York. Apple E-book.

Lippman, S. A. and McCall, J. J. (1976). The Economics of Job Search: A Survey. Economic Inquiry, 14(2):155-189.

Manso, G. (2011). Motivating Innovation. The Journal of Finance, 66(5):1823-1860.

March, J. G. (1991). Exploration and Exploitation in Organizational Learning. Organization Science, 2(1):71-87.

March, J. G. and Shapira, Z. (1987). Managerial Perspectives on Risk and Risk Taking. Management Science, 33(11):1404-1418.

Mebane Jr., W. R. and Sekhon, J. S. (2011). Genetic Optimization Using Derivatives: The Rgenoud Package for R. Journal of Statistical Software, 42(11):1-26.

Nobel, P. (2005). Sixteen Acres: Architecture and the Outrageous Struggle for the Future of Ground Zero. Metropolitan Books, New York.

Nosek, B. A. and Lakens, D. (2014). Registered reports: A method to increase the credibility of published results. Social Psychology, 45(3):137-141.

O'Reilly, C. A. and Tushman, M. L. (2013). Organizational Ambidexterity: Past, Present, and Future. Academy of Management Perspectives, 27(4):324-338.

Pfeffer, J. and Sutton, R. I. (2006a). Evidence-based Management. Harvard Business Review.

Pfeffer, J. and Sutton, R. I. (2006b). Hard Facts, Dangerous Half-Truths, and Total Nonsense. Harvard Business School Press, Boston.

Polanyi, M. (2009). The Tacit Dimension. University of Chicago press, Chicago.

Pondy, L. R. (1992). Reflections on Organizational Conflict. Journal of Organizational Behavior, $13: 257-261$.

Rivkin, J. W. (2000). Imitation of Complex Strategies. Management Science, 46(6):824-844. 
Rivkin, J. W. and Siggelkow, N. (2003). Balancing Search and Stability: Interdependencies Among Elements of Organizational Design. Management Science, 49(3):290-311.

Roberts, J., Saloner, G., and Gibbons, R. (2012). Strategy in Organizations. In Gibbons, R. and Roberts, J., editors, The Handbook of Organizational Economics, pages 373-431. Princeton University Press, Princeton.

Schilling, M. A. and Fang, C. (2014). When Hubs Forget, Lie, and Play Favorites: Interpersonal Network Structure, Information Distortion, and Organizational Learning. Strategic Management Journal, 35(7):974-994.

Shapira, Z. (1995). Risk Taking: A Managerial Perspective. Russell Sage Foundation.

Stinchcombe, A. L. (1990). Information and Organizations. Number 19 in California Series on Social Choice and Political Economy. University of California Press, Berkeley.

Sutton, R. I. and Hoyt, D. (2016). Better Service, Faster: A Design Thinking Case Study. Harvard Business Review.

Tushman, M. L. and Anderson, P. (1986). Technological Discontinuities and Organizational Environments. Administrative Science Quarterly, 31(3):439-465.

Tushman, M. L. and O'Reilly, C. A. (1996). The Ambidextrous Organizations: Managing Evolutionary and Revolutionary Change. California Management Review, 38(4):8-30.

Utterback, J. (1994). Mastering the Dynamics of Innovation: How Companies Can Seize Opportunities in the Face of Technological Change. Harvard Business School Press, Boston.

Winter, S. G., Cattani, G., and Dorsch, A. (2007). The Value of Moderate Obsession: Insights from a New Model of Organizational Search. Organization Science, 18(3):403-419.

Wyatt, E. (2002). Blueprint for Ground Zero Begins to Take Shape. The New York Times, page A1.

Wyatt, E. (2003). Spotlight Is on Wedge Of Light, Symbol or Not. The New York Times. 
Figures 
Figure 1: World Trade Center Master Plans from Studio Daniel Libeskind

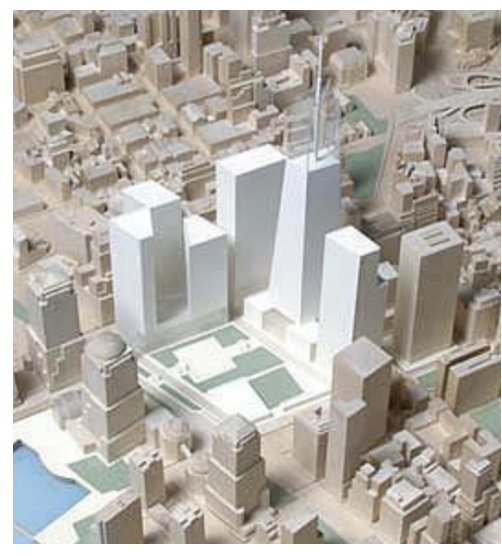

(a) Initial Design

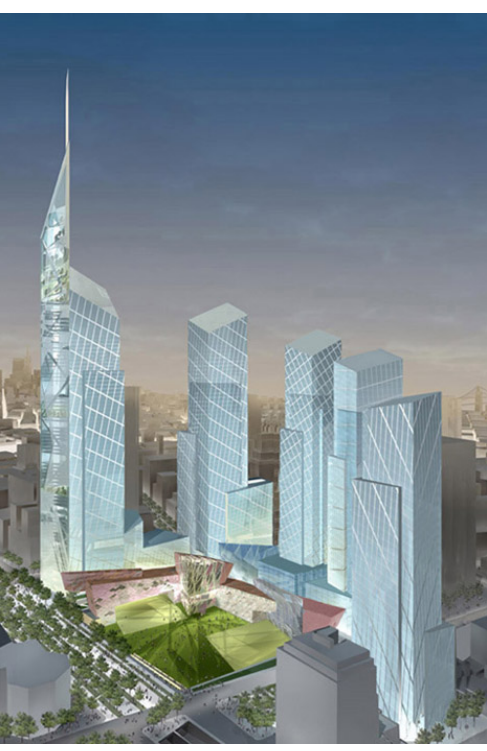

(b) Libeskind Proposal

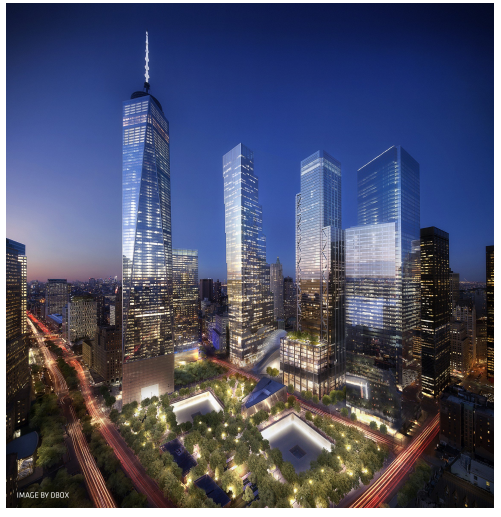

(c) Final Plan

Figure 2: Model Flow

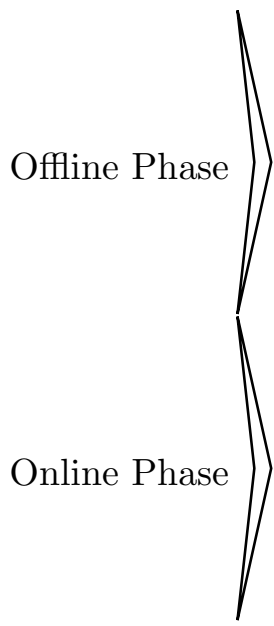

Organization selects manager

Manager chooses offline strategy

Offline outcome revealed

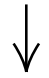

Organization retains incumbent or selects replacement

Chosen manager chooses online strategy

Online outcome revealed

Figure 3: Classes of Fitness Landscapes, Levinthal and Warglien (1999) and Winter et al. (2007)

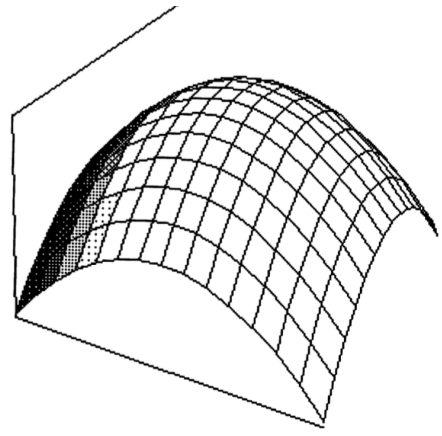

(a) Smooth Landscape

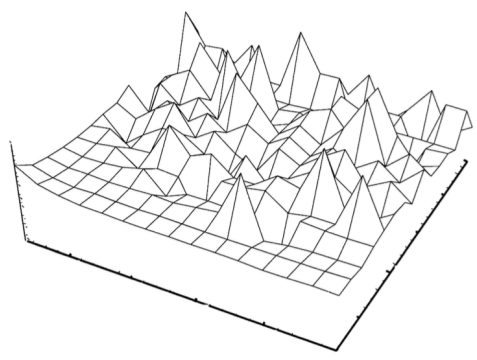

(b) Rugged Landscape

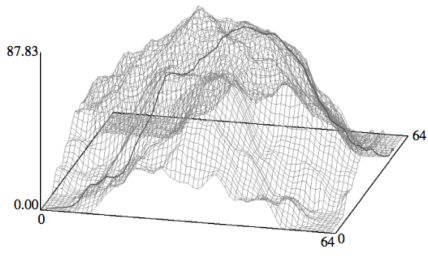

(c) Smooth-Rugged Hybrid 
Figure 4: Generating a Rugged Landscape Using Brownian Motion

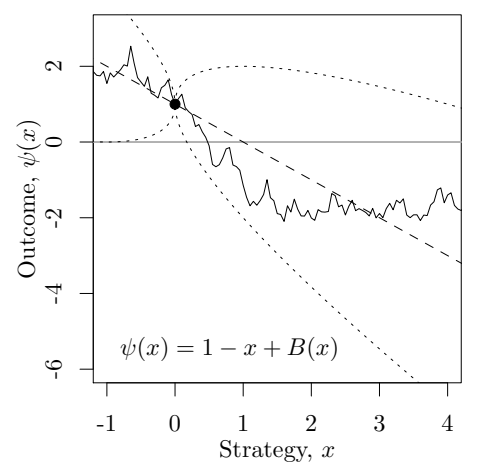

(a) Outcomes $=\mathrm{f}($ Strategies $)$

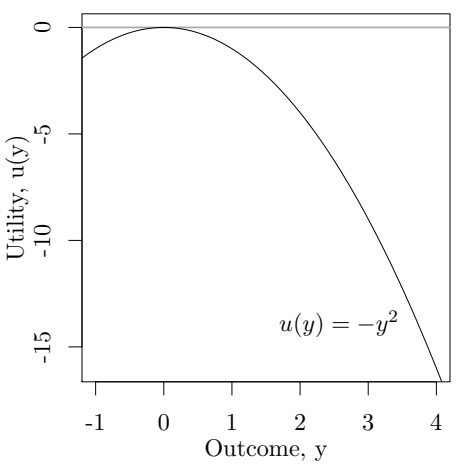

(b) Utility $=\mathrm{f}($ Outcomes $)$

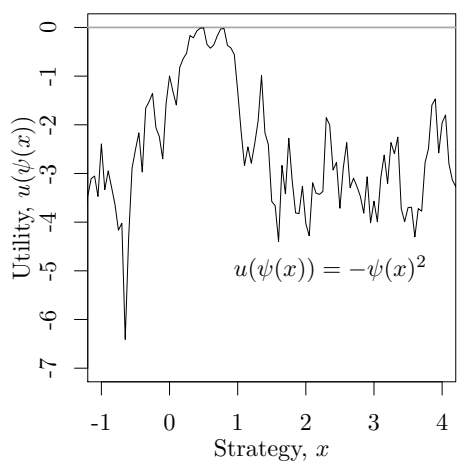

(c) Utility $=\mathrm{f}($ Strategies $)$

Figure 5: Outcomes and Utility as a Function of Two Offline Strategies

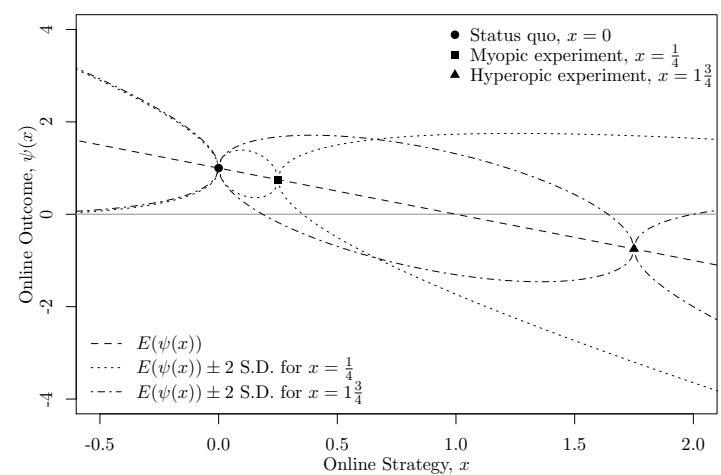

(a) Online Outcomes $=\mathrm{f}($ Offline Strategies $)$

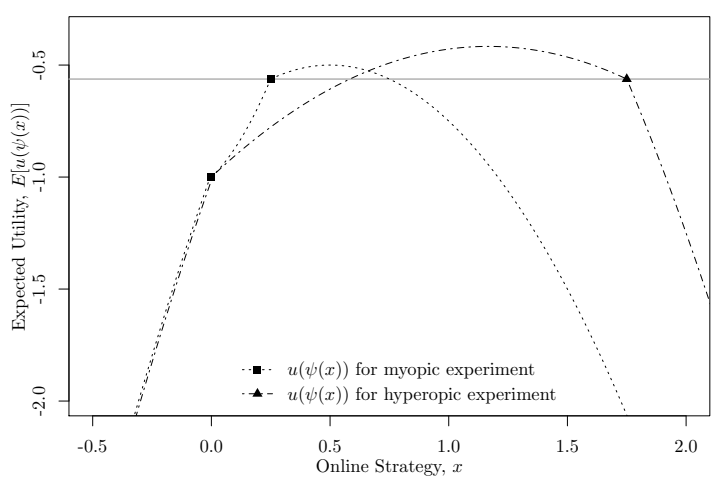

(b) Online Utility $=\mathrm{f}($ Offline Strategies $)$

Figure 6: Outcomes and Utility as a Function of Two Manager's Strategies

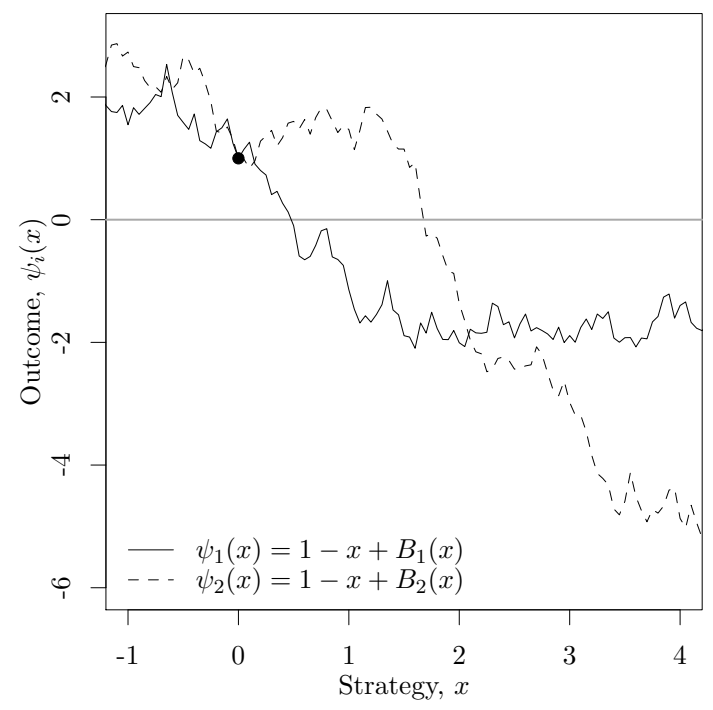

(a) Outcomes $=\mathrm{f}($ Strategies $)$

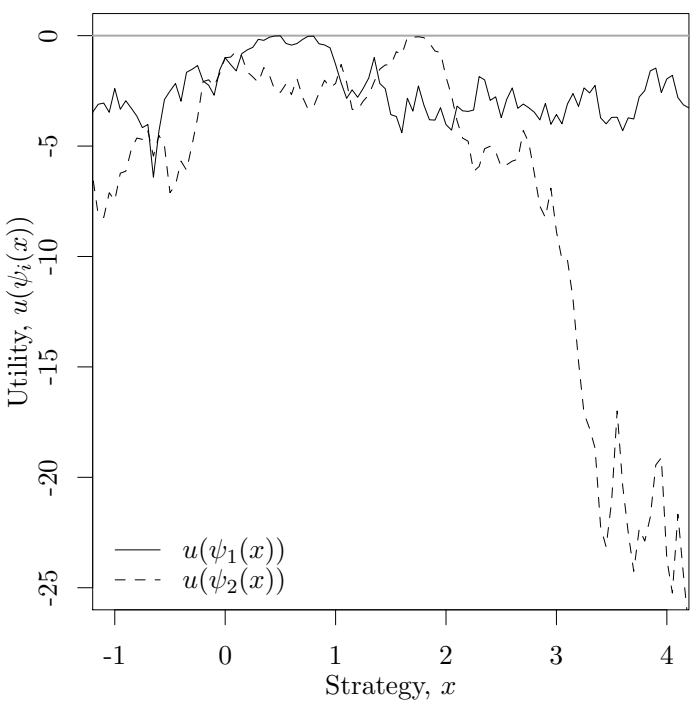

(b) Utility $=\mathrm{f}($ Strategies $)$ 
Figure 7: Online Strategies Conditional on Offline Strategy-Outcome Pairs

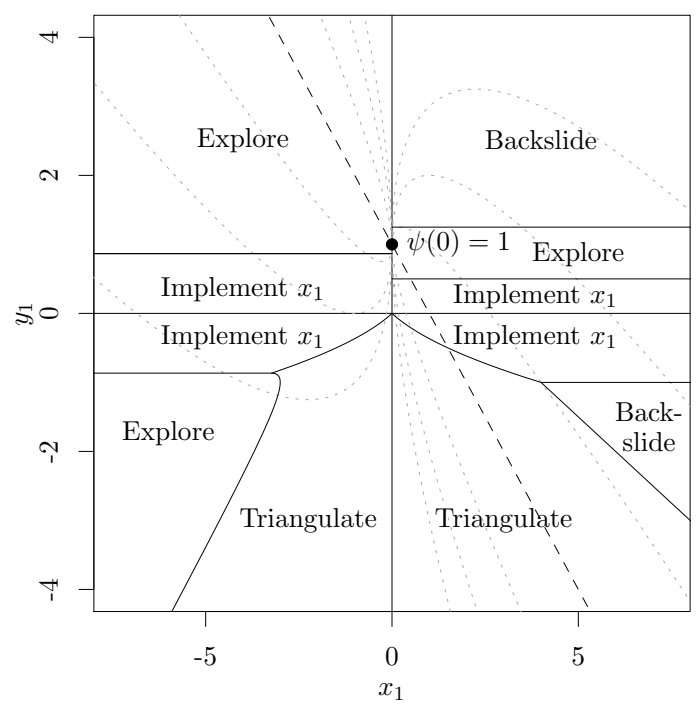

(a) $\sigma=1$

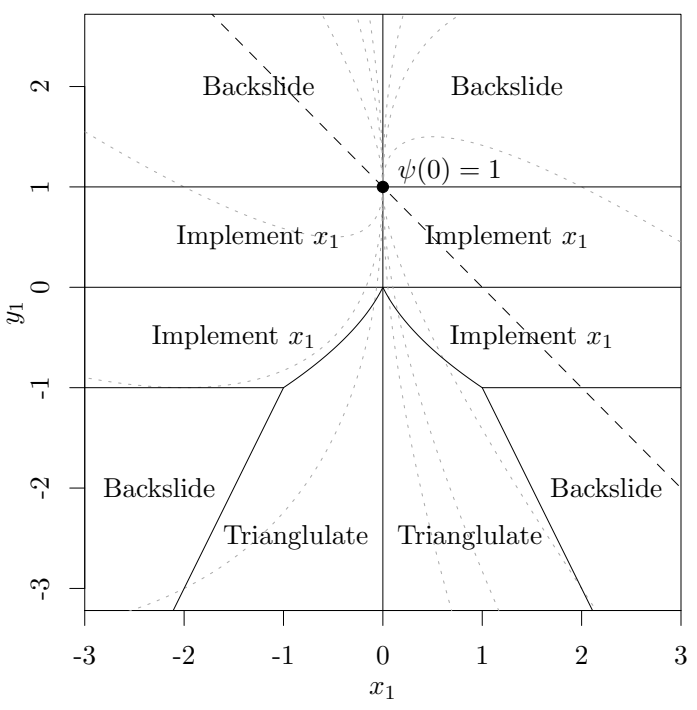

(b) $\sigma=2$

Figure 8: Equilibrium Offline Strategy: Observable Offline Strategy and Commitment

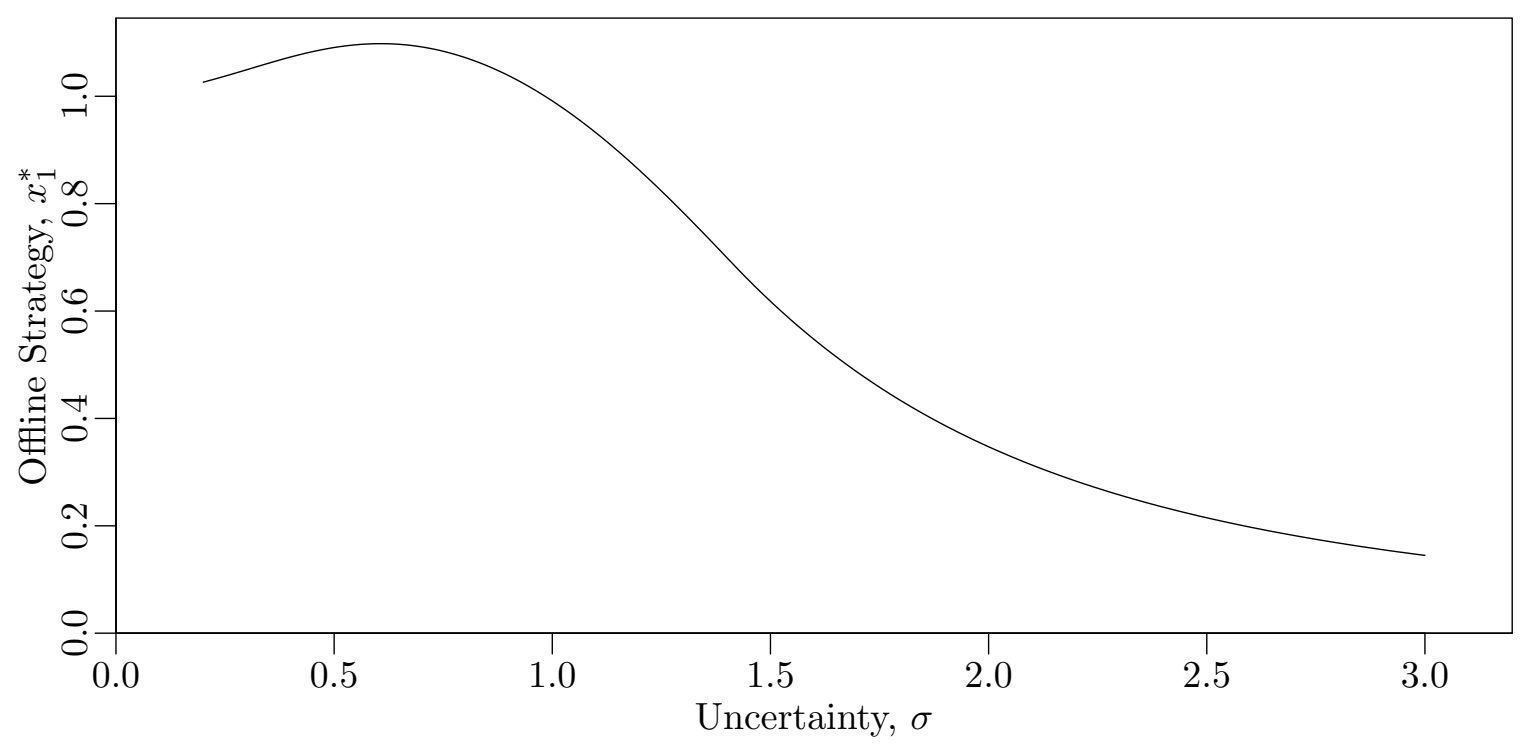


Figure 9: Replacement Decisions for Observable Strategy and No Commitment

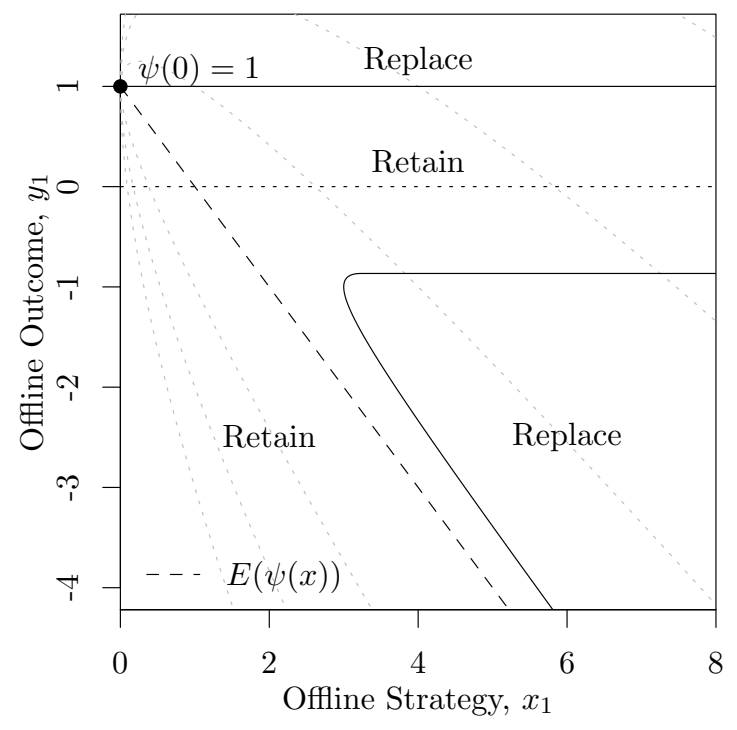

(a) $\sigma=1$

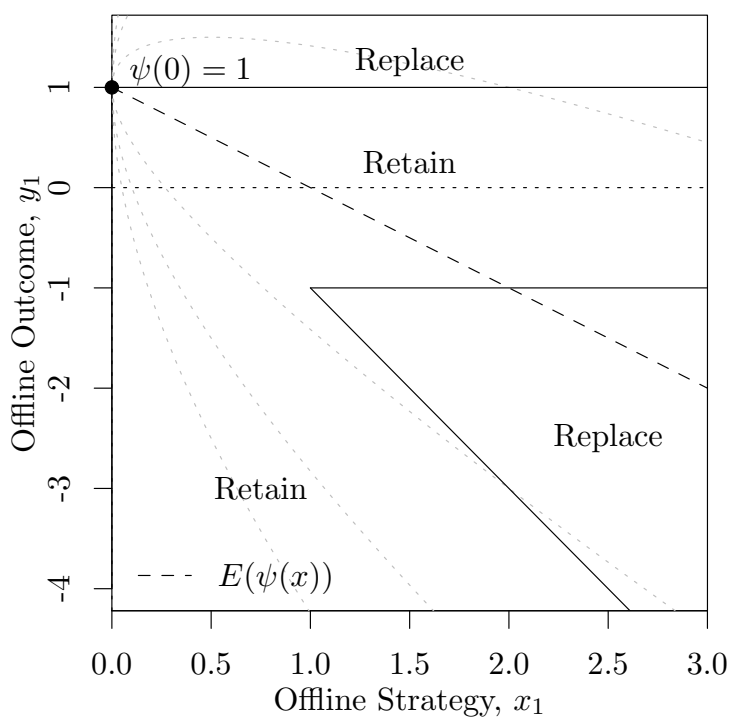

(b) $\sigma=2$

Figure 10: Replacement Probabilities Conditional on Offline Strategy

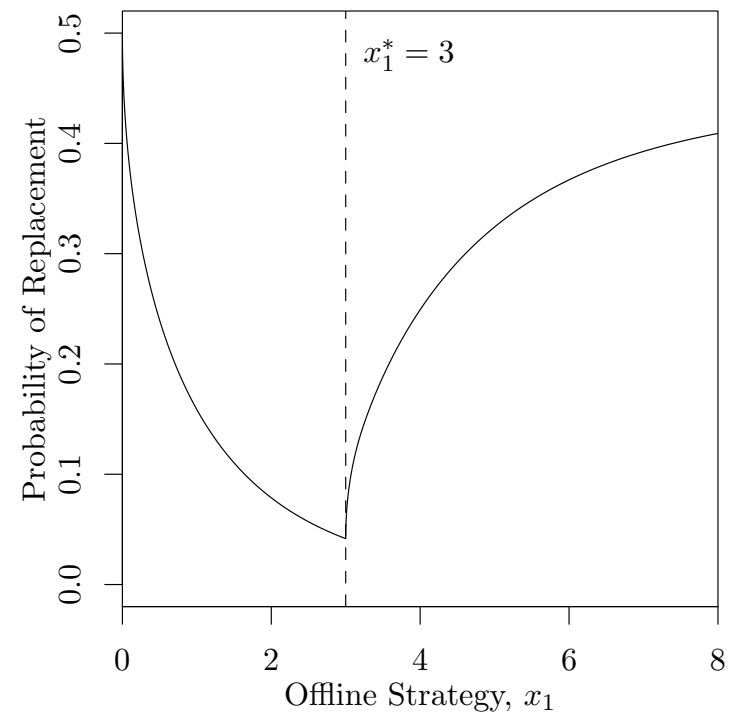

(a) $\sigma=1$

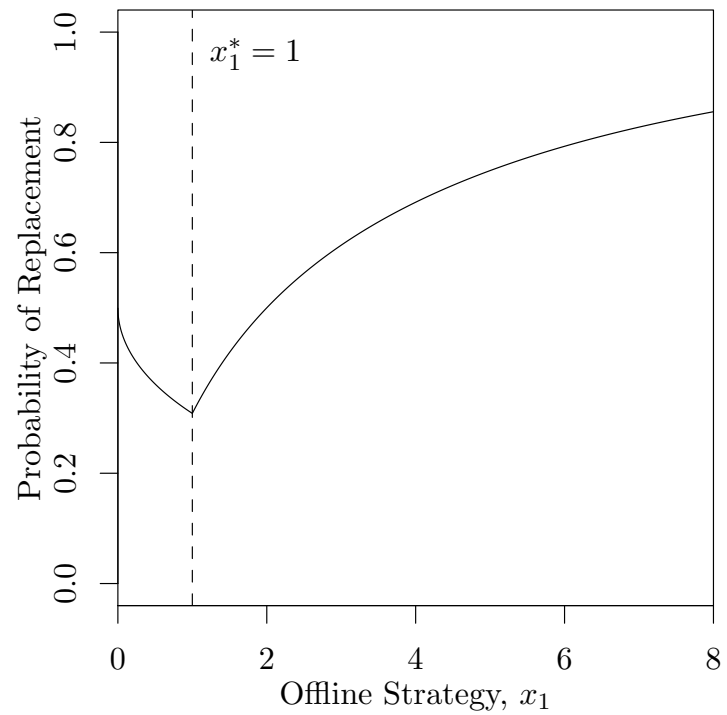

(b) $\sigma=2$ 
Figure 11: Equilibrium Offline Strategy: Observable Strategy and No Commitment

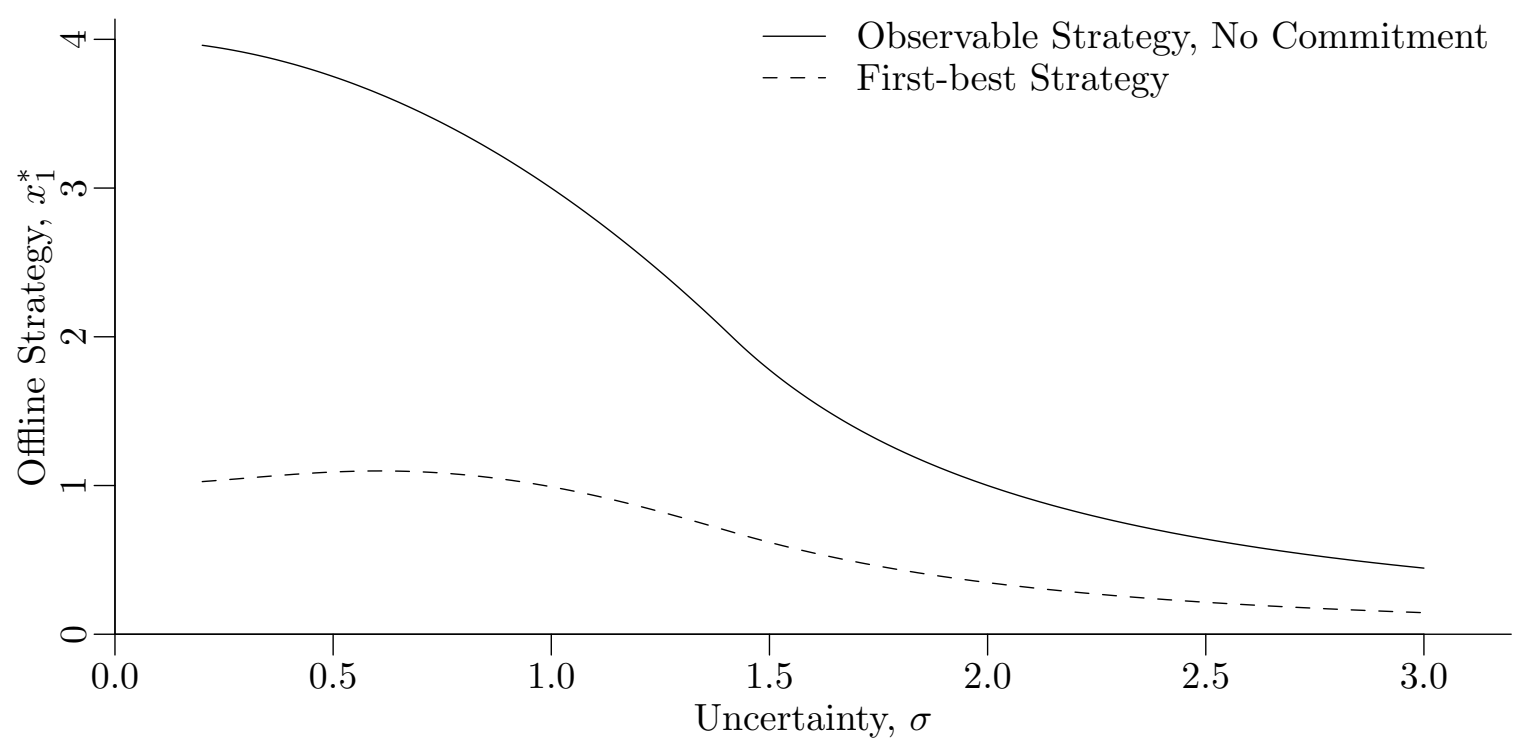

Figure 12: Equilibrium Offline Strategy: Tacit Strategy and Tenure Guarantee

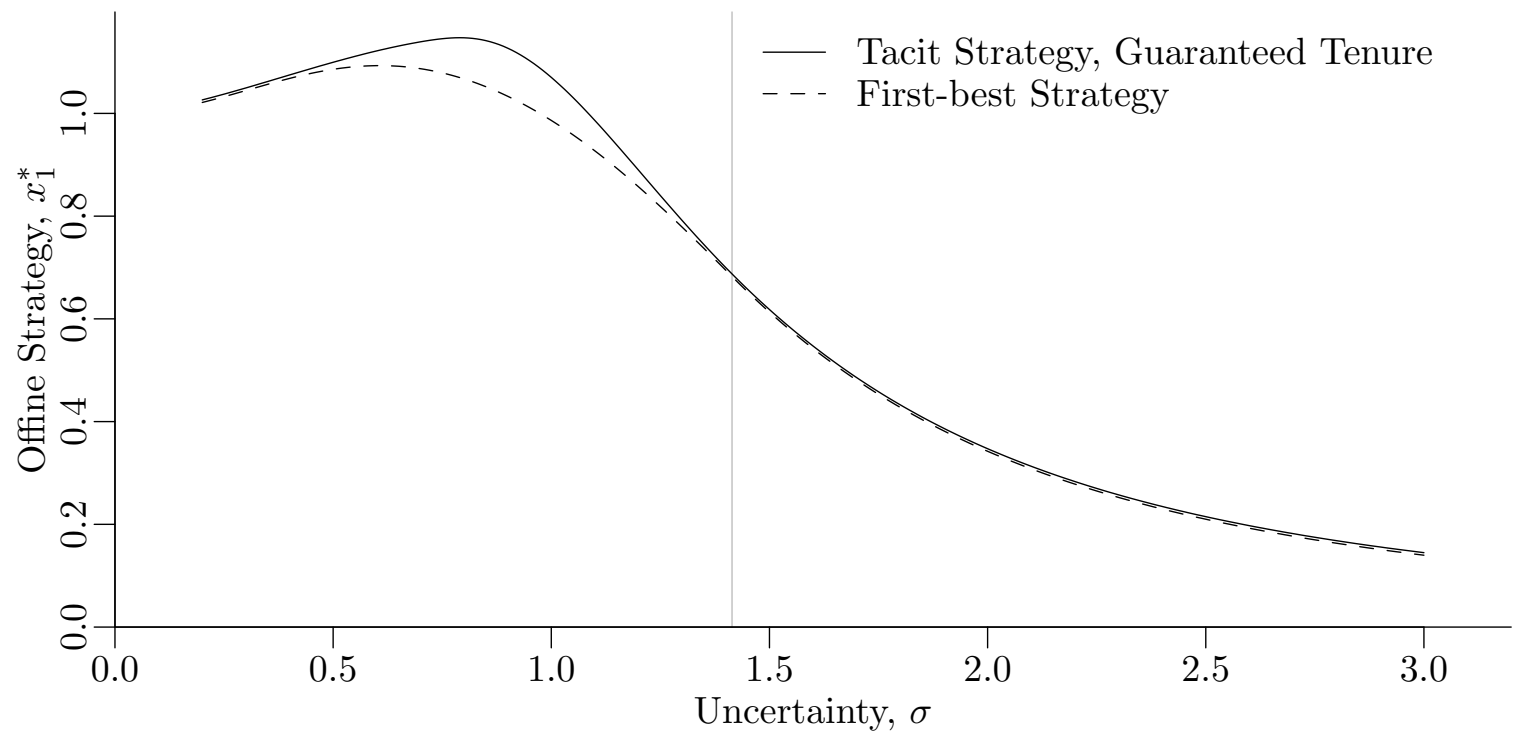


Figure 13: Equilibrium Offline Strategy: Tacit Strategy and Outcome-based Replacement

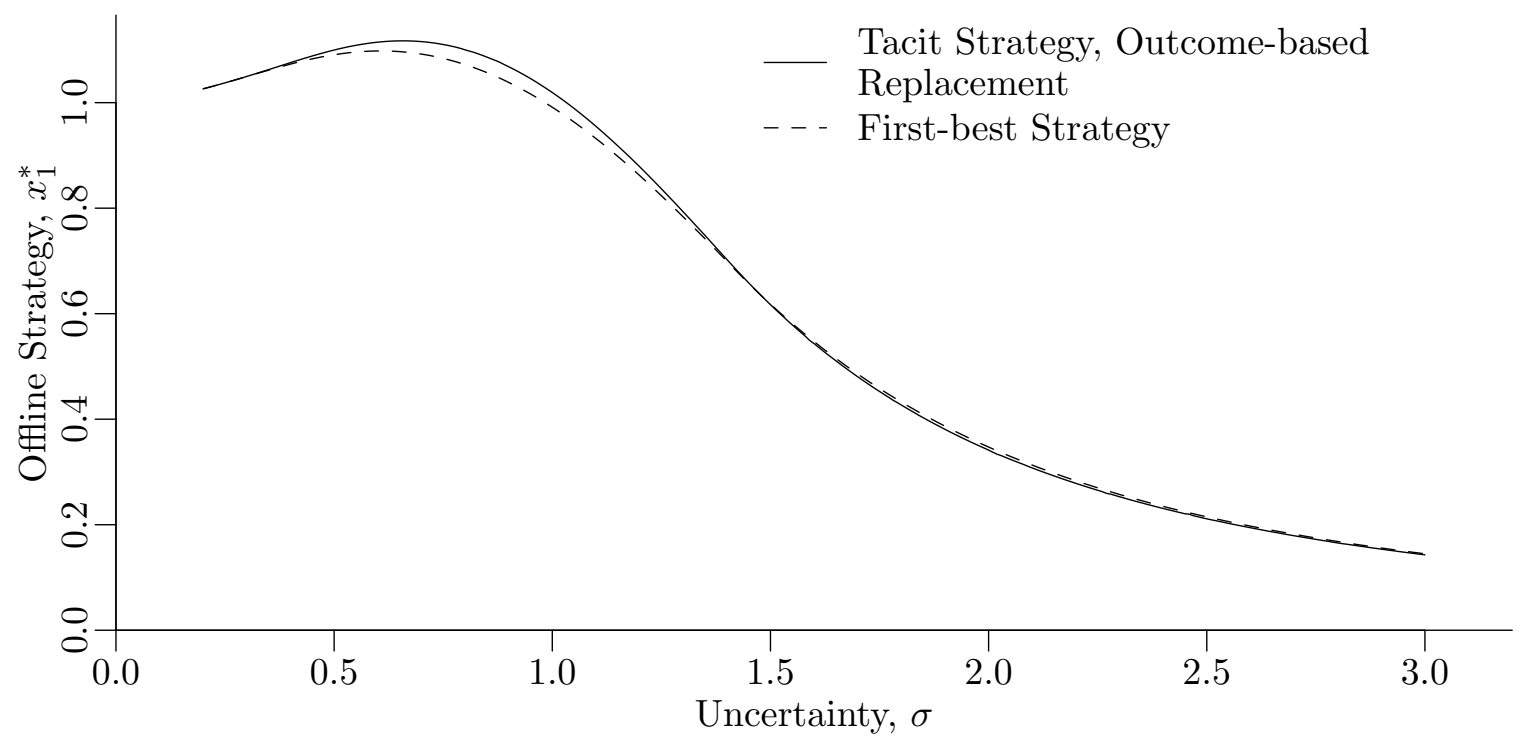

Figure 14: Comparing Tenure Guarantee and Outcome-based Replacement

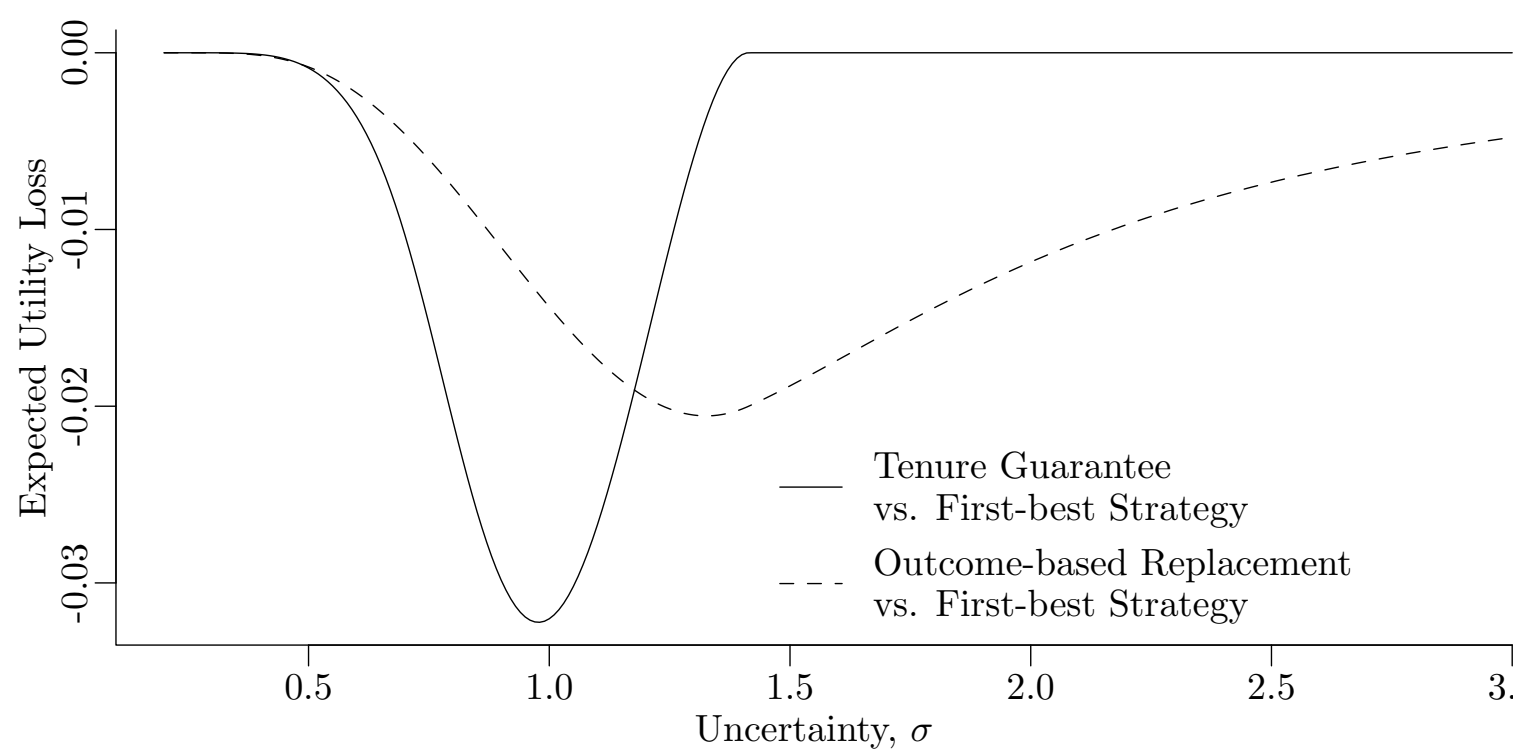

